\title{
Secondary inorganic aerosol simulations for Europe with special attention to nitrate
}

\author{
M. Schaap ${ }^{1,2}$, M. van Loon ${ }^{2}$, H. M. ten Brink ${ }^{3}$, F. J. Dentener ${ }^{4}$, and P. J. H. Builtjes ${ }^{1,2}$ \\ ${ }^{1}$ University of Utrecht, Institute of Marine and Atmospheric Science, PO Box 80005, 3508 TA, Utrecht, The Netherlands \\ ${ }^{2}$ TNO Institute of Environmental Sciences, Energy and Process Innovation, PO Box 342, 7300 AH Apeldoorn, The \\ Netherlands \\ ${ }^{3}$ Netherlands Energy Research Foundation (ECN), PO Box 1, 1755 LE Petten, The Netherlands \\ ${ }^{4}$ Joint Research Centre (JRC), Institute for Environment and Sustainability, 21020 Ispra, Italy
}

Received: 1 July 2003 - Published in Atmos. Chem. Phys. Discuss.: 21 November 2003

Revised: 7 May 2004 - Accepted: 4 June 2004 - Published: 15 June 2004

\begin{abstract}
Nitrate is an important component of (secondary inorganic) fine aerosols in Europe. We present a model simulation for the year 1995 in which we account for the formation of secondary inorganic aerosols including ammonium sulphate and ammonium nitrate, a semi volatile component. For this purpose, the chemistry-transport model LOTOS was extended with a thermodynamic equilibrium module and additional relevant processes to account for secondary aerosol formation and deposition. During winter, fall and especially spring high nitrate levels are projected over north western, central and eastern Europe. During winter nitrate concentrations are highest in Italy, in accordance with observed data. In winter nitric acid, the precursor for aerosol nitrate is formed through heterogeneous reactions on the surface of aerosols. Modelled and observed sulphate concentrations show little seasonal variation. Compared to sulphate levels, appreciable ammonium nitrate concentrations in summer are limited to those areas with high ammonia emissions, e.g. the Netherlands, since high ammonia concentrations are necessary to stabilise this aerosol component at high temperatures. As a consequence of the strong seasonal variation in nitrate levels the AOD depth of nitrate over Europe is especially significant compared to that of sulphate in winter and spring when equal AOD values are calculated over large parts of Europe. Averaged over all stations the model reproduces the measured concentrations for $\mathrm{NO}_{3}, \mathrm{SO}_{4}, \mathrm{NH}_{4}$, $\mathrm{TNO}_{3}\left(\mathrm{HNO}_{3}+\mathrm{NO}_{3}\right), \mathrm{TNH}_{4}\left(\mathrm{NH}_{3}+\mathrm{NH}_{4}\right)$ and $\mathrm{SO}_{2}$ within $20 \%$. The daily variation is captured well, albeit that the model does not always represent the amplitude of single events. The model underestimates wet deposition which was attributed to the crude representation of cloud processes. Comparison of retrieved and computed aerosol optical depth (AOD) showed that the model underestimates AOD signifi-
\end{abstract}

Correspondence to: M. Schaap

(m.schaap@mep.tno.nl) cantly, which was expected due to the lack of carbonaceous aerosols, sea salt and dust in the model. The treatment of ammonia was found to be a major source for uncertainties in the model representation of secondary aerosols. Also, inclusion of sea salt is necessary to properly assess the nitrate and nitric acid levels in marine areas.

\section{Introduction}

Aerosols of an anthropogenic origin play a key role in changing the Earth's radiation budget. Aerosols directly scatter and/or absorb solar radiation. Indirectly, they influence the micro-physical properties of clouds and therewith their effective albedo. Over polluted continental regions the direct forcing of sulphate alone can be as large as those of the combined greenhouse gases, but opposite of sign (e.g. Charlson et al., 1992; Kiehl et al., 1993). In the last decade the influence of a number of other aerosol components, like organic carbon, black carbon and (anthropogenicly derived) mineral dust, on the radiation budget has also been shown (IPCC, 2001, and references therein). However, IPCC (2001) did not present a best estimate for the direct forcing by nitrate, mostly because of a lack of reliable measurement data on this semi volatile compound.

A recent critical assessment of nitrate observations in Europe showed that nitrate significantly contributes to the aerosol concentration in Northern Europe (Schaap et al., 2002a). Especially in winter (October-March) large contributions of nitrate to the total aerosol mass were found in western Europe, where nitrate concentrations often exceeded those of sulphate. At continental sites nitrate is mainly present in the fine aerosol mode (Ten Brink et al., 1997; Heintzenberg et al., 1998; Putaud et al., 2003). The aerosols in this size range scatter UV-VIS light most efficiently, which 

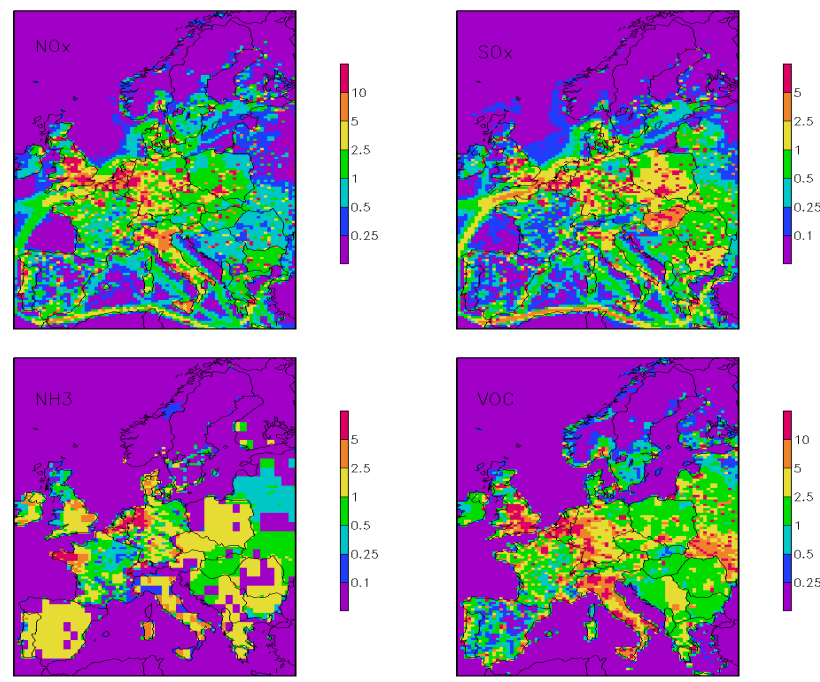

Fig. 1. Distribution of the emissions (Ktonnes/yr)of $\mathrm{NO}_{\mathrm{x}}\left(\right.$ as $\left.\mathrm{NO}_{2}\right)$, $\mathrm{SO}_{\mathrm{x}}\left(\right.$ as $\left.\mathrm{SO}_{2}\right), \mathrm{NH}_{3}$ and VOC.

indicates that nitrate could exert a significant climate forcing over continental Europe in winter (Ten Brink and Schaap, 2002) and regionally even during summer (Ten Brink et al., 1997). The latter was also recognised in a comparison of model results with aerosol optical depth obtained from the ATSR2 satellite for August 1997 (Jeuken et al., 2001; Robles-Gonzales et al., 2003).

Sub-micron nitrate is predominantly present in the form of ammonium nitrate $\left(\mathrm{NH}_{4} \mathrm{NO}_{3}\right)$, a semi-volatile compound:

$\mathrm{NH}_{3}+\mathrm{HNO}_{3} \leftrightarrow \mathrm{NH}_{4} \mathrm{NO}_{3}$.

The equilibrium between ammonium nitrate and its gaseous precursors is relatively well understood (e.g. Basset and Seinfeld, 1983; Mozurkewich, 1993; Nenes et al., 1998; Zhang et al., 2000). The gas-aerosol partitioning of nitrate depends strongly on the availability of its precursor gasses and on the ambient conditions (Ansari and Pandis, 1998). Atmospheric ammonia is first neutralized by sulphuric acid $\left(\mathrm{H}_{2} \mathrm{SO}_{4}\right)$ to form ammonium sulphate $\left(\left(\mathrm{NH}_{4}\right)_{2} \mathrm{SO}_{4}\right)$. Remaining ammonia may then combine with nitric acid to form ammonium nitrate. Model sensitivity studies have shown that under conditions where ammonia limits the formation of nitrate a decline in sulphate concentrations may result in a subsequent rise of the nitrate levels (Ansari and Pandis, 1998; West et al., 1999; Metzger et al., 2002a). This results in a non linear response of fine aerosol mass and aerosol forcing to changes in aerosol precursor concentrations (West et al., 1998). Hence, a thorough knowledge of the processes involved in the formation of nitrate is needed to assess its future role in climate change.

Although nitrate was routinely included in the calculations of regional scale models like the European EMEP model, the results received little attention. Much more emphasis was drawn to the importance of ammonium nitrate by the global model studies of Metzger et al. (2002b) and Adams et al. (1999) showing that nitrate was an important component of aerosols over large (continental) areas in the world. Moreover, Adams et al. (2001) found nitrate in the year 2100 to be more important than sulphate with respect to aerosol radiative forcing. These studies used a model with a resolution of 2.5 by $2.5^{\circ}$ or coarser. However, satellite retrieved aerosol optical depth (AOD) fields over Europe show a large spatial variation and strong gradients around industrialized areas, indicating the influence on AOD of local emissions of primary aerosols and/or precursor gases (Robles Gonzalez et al., 2000). Ammonia is one of such precursors with strong gradients in the emission distribution, which is associated with large concentration gradients of ammonia and associated ammonium nitrate. Therefore, we expect that a model with a higher horizontal resolution is more suitable to assess aerosol and especially ammonium nitrate fields than global models.

We evaluate the secondary inorganic aerosol concentrations over Europe with special attention to nitrate using the three-dimensional (3-D), $25 \mathrm{~km}$ resolution, European scale, LOTOS model. In the next section the LOTOS model set-up is introduced. In Sect. 3 the results for the year 1995 are presented and compared to measured data. Section 4 describes the results of AOD and forcing calculations performed in this study. Discussion and conclusions follow in Sect. 5. A detailed study of the sensitivity of the calculated nitrate concentrations to emissions is presented in a seperate publication (Schaap, 2003).

\section{Description of the LOTOS model}

\subsection{Background}

The model employed in this study is the semi-3-D chemistrytransport model LOTOS that was developed for LOng Term Ozone Simulations. It is of intermediate complexity in the sense that the relevant processes are parameterised in such a way that the computational demands are modest enabling hour-by-hour calculations over extended periods of one or more years within acceptable CPU time, even on a workstation or a PC. LOTOS was originally developed and used as a photo-oxidant model (Builtjes, 1992; Hass et al., 1997; Roemer et al., 2003). Recently, the photochemical module was extended to simulate the inorganic secondary aerosols $\mathrm{SO}_{4}$, $\mathrm{NH}_{4}$ and $\mathrm{NO}_{3}$. The model setup presented below is LOTOS version 5.2, which was used here to perform calculations for the full year of 1995 .

\subsection{Model structure}

LOTOS was ran for the region that spans from $10^{\circ} \mathrm{W}$ to $40^{\circ} \mathrm{E}$ and from $35^{\circ} \mathrm{N}$ to $70^{\circ} \mathrm{N}$ with a spatial resolution of $0.5 \times 0.25^{\circ}$ lon-lat, roughly corresponding to 25 by $25 \mathrm{~km}$. The vertical extent of the model is $3.5 \mathrm{~km}$ (above sea level). 
Table 1. Total emissions of $\mathrm{SO}_{\mathrm{x}}, \mathrm{NO}_{\mathrm{x}}, \mathrm{VOC}, \mathrm{CH}_{4}, \mathrm{CO}$ and $\mathrm{NH}_{3}$ for the year 1995 (Ktonnes) for anthropogenic activities in Europe excluding the former USSR.

\begin{tabular}{clcccccc}
\hline SNAP $^{\mathrm{a}}$ & Description & $\mathrm{SO}_{\mathrm{x}}$ & $\mathrm{NO}_{\mathrm{x}}$ & $\mathrm{VOC}$ & $\mathrm{CH}_{4}$ & $\mathrm{CO}$ & $\mathrm{NH}_{3}$ \\
\hline 1 & Energy transformation & 1,2382 & 3,738 & 169 & 111 & 645 & 8 \\
2 & Small combustion sources & 2,147 & 803 & 820 & 496 & 9,939 & 2 \\
3 & Industrial combustion & 2,948 & 1,617 & 115 & 69 & 3,884 & 2 \\
4 & Industrial process emissions & 550 & 326 & 1,350 & 85 & 2,898 & 119 \\
5 & Extraction of fossil fuels & 36 & 112 & 1,149 & 5,811 & 105 & 0 \\
6 & Solvent and product use & 0 & 0 & 4,580 & 0 & 0 & 3 \\
7 & Road transport & 689 & 6,854 & 5,931 & 207 & 31,988 & 52 \\
8 & Non road transport & 296 & 2,142 & 775 & 19 & 2,837 & 0 \\
9 & Waste handling and disposal & 92 & 105 & 231 & 9,297 & 2,916 & 92 \\
10 & Agriculture & 0 & 26 & 223 & 12,052 & 278 & 4,344 \\
& Total & 19,139 & 15,721 & 15,344 & 28,147 & 55,489 & 4,621 \\
\hline
\end{tabular}

a Selected nomenclature air pollution.

The vertical domain is divided in three layers. The lowest layer represents the variable mixing layer on top of which two layers with equal, but variable, depth are located. Due to the continuously changing mixing height, the grid volumes vary in space and time. The mixing height is part of the meteorological input for 1995, which is diagnostic and derived from ECMWF using procedures developed by the Free University of Berlin (Kerschbaumer and Reimer, 2003). Every hour, the mixing layer height is updated and the mass in the three layers is redistributed by mass conserving linear interpolation. The vertical coverage of the model is considered sufficient for the purpose of this study, since it has been shown that in 80 to $90 \%$ of the time the aerosol load above $3 \mathrm{~km}$ is negligible (ten Brink et al., 2001). To compare the calculated concentrations with measurements the concentration of each compound is calculated at a reference height of $2 \mathrm{~m}$ using vertical profile information derived from the deposition parametrisation.

\subsection{Emissions}

The inventories of the antropogenic emissions of $\mathrm{SO}_{\mathrm{x}}, \mathrm{NO}_{\mathrm{x}}$, NM-VOC, $\mathrm{CO}, \mathrm{CH}_{4}, \mathrm{NH}_{3}$ are based on CORINAIR 1995 data version 2.2 (Builtjes et al., 2003). The country totals have been gridded on the LOTOS grid following the methodology of the CEPMEIP project (TNO, 2001). The inventories use the source categories following the Selected Nomenclature Air Pollution (SNAP). The emission totals for each SNAP level 1 category used in this study are listed in Table 1. Only for traffic a further subdivision has been made into gasoline exhaust, diesel exhaust and fuel evaporation. In Fig. 1 annual gridded yearly averages are shown of a number of emitted compounds. Note that the ship emissions for 1995 are taken from EMEP (EMEP, 2002).

The temporal variation of the emissions is represented by time factors. For each source category a monthly factor breaks down the annual total into monthly value. This value is divided by a factor for the day of the week (i.e. Monday, Tuesday, etc.) and finally by a factor for the hour of the day (local time). Except for ammonia, these factors are obtained from the TROTREP project (Builtjes et al., 2003). In comparison with the emissions of $\mathrm{SO}_{\mathrm{x}}, \mathrm{NO}_{\mathrm{x}}$, and $\mathrm{VOC}$, the emission of ammonia is uncertain and not as well understood. Ammonia emissions in Europe are for the largest part (80-95\%) associated with agricultural activities (van der Hoek, 1998). The seasonal variation in ammonia emissions is uncertain and may differ regionally as function of farming procedures and climatic conditions. The seasonal variation in the ammonia emissions is modelled based on experimental data representative for The Netherlands as shown in Fig. 2 (Bogaard and Duyzer, 1997). The seasonal variation shows a distinct maximum in March and a slight maximum in August due to the application of manure on top of a function that roughly scales with duration of daylight. Following Asman (2001) we assumed a diurnal cycle in the emission with half the average value at midnight and twice the average at noon.

Exchange, emission or deposition, of ammonia depends on the compensation point, which refers to the situation in which the ammonia concentration in air is in equilibrium with the vegetation. Assessing the compensation point of ammonia is not possible for many surfaces (Asman, 2001). In addition, the presence of a compensation point is probably most important in relatively remote regions away from the main sources. Close to sources ammonia exchange will be dominated by deposition. We can therefore safely describe emission and deposition separately.

Due to the emissions there is a large vertical gradient of ammonia concentrations in the source areas with highest concentrations near the ground. However, in our model the emissions are completely vertically mixed over the first mixing layer. We may therefore underestimate the effective 


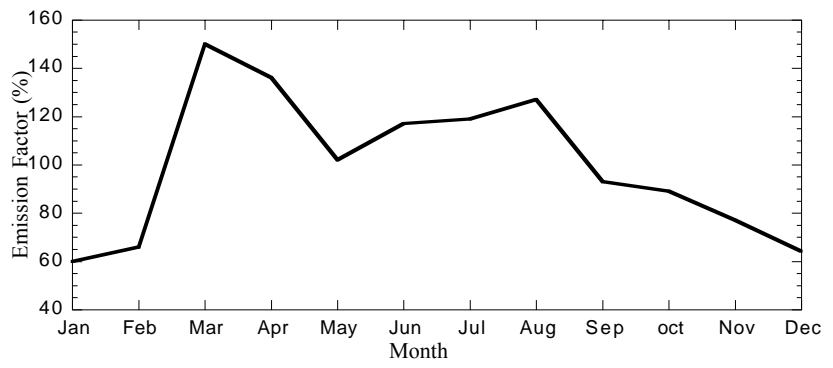

Fig. 2. Monthly emission factor for ammonia (source: Bogaard and Duyzer, 1997).

dry deposition of ammonia close to the sources. To account for this effect Asman and Janssen (1987) and Dentener and Crutzen (1994) lowered the "effective" emissions in their model by $25 \%$, assuming that this part of the emission was removed on subgrid scales. Janssen and Asman (1988) argued that by uniformly lowering the ammonia emission, ammonium formation could be underestimated and more sophisticated correction factors were proposed. These correction factors would be highly variable depending on region, the surface roughness downwind of the sources, availability of acidic precursors, meteorological conditions and the history of the air parcel (e.g. Asman, 1998). Much of this information is not available in our model and therefore no correction factors are used in this study.

The large uncertainty in the ammonia emissions, the seasonal variation and the use of correction factors is further discussed in a separate publication, Schaap (2003).

\subsection{Chemistry}

Gasphase photochemistry in LOTOS is described using a modified version of the CBM-IV mechanism (Whitten et al., 1980). The mechanism was tested against the results of an intercomparison presented by Poppe et al. (1996) and found to be in good agreement with the results presented for the other mechanisms. The photolysis rates are calculated following Poppe et al. (1996). The chemical differential equations are solved using TWOSTEP (Verwer, 1994). The chemistry scheme further includes gas phase and heterogeneous reactions leading to secondary aerosol formation.

The reaction of $\mathrm{N}_{2} \mathrm{O}_{5}$ on aerosol surfaces has been proposed to play an important role in tropospheric chemistry (Dentener and Crutzen, 1993). This reaction is a source for nitric acid during nighttime, whereas during the day the $\mathrm{NO}_{3}$ radical is readily photolysed. We parametrised this reaction following Dentener and Crutzen (1993). In this parametrisation typical lognormal accumulation mode parameters $(\operatorname{Dg}(\mathrm{N})=0.068 \mu \mathrm{m}, \sigma=2.0)$ (Whitby, 1978) are used for the size distribution of the dry aerosol. The wet aerosol size distribution is calculated using the aerosol associated water obtained from the aerosol thermodynamics module (see below). The reaction probability of $\mathrm{N}_{2} \mathrm{O}_{5}$ on the aerosol surface has been determined for various solutions. Reaction probabilities between 0.01 and 0.2 were found (Jacob, 2000, and references therein). A recent study by Mentel et al. (1999) indicates values at the lower part of this range. Therefore, we use a probability of $\gamma=0.05$, which is somewhat lower than the generally used recommendation by Jacob (2000). In the polluted lower troposphere of Europe, however, the hydrolysis on the aerosol surfaces is fast, with lifetimes of $\mathrm{N}_{2} \mathrm{O}_{5}$ less than an hour (Dentener and Crutzen, 1993). Therefore the exact value of $\gamma$ is not determining the results strongly. Due to the limited availability on cloud information, we neglect the role of clouds on the hydrolysis of $\mathrm{N}_{2} \mathrm{O}_{5}$, which may also contribute to nitric acid formation. However, due to the very fast reaction of $\mathrm{N}_{2} \mathrm{O}_{5}$ on aerosol in polluted Europe, the role of clouds on $\mathrm{N}_{2} \mathrm{O}_{5}$ hydrolysis is probably less important.

The ISORROPIA thermodynamic equilibrium module (Nenes et al., 1998) is used to describe the equilibrium between gaseous nitric acid, ammonia and particulate ammonium nitrate and ammonium sulphate and aerosol water. In this work we assume equilibrium between the aerosol and gas phase at all times. For sub-micron aerosol this equilibrium assumption is valid in most cases, but it may not be valid for coarse fraction aerosol (Meng and Seinfeld, 1996). However, since our model does currently not incorporate sea salt or dust, which are sinks for gaseous nitric acid, the results of our equilibrium calculations over marine and arid regions should not be overinterpreted (Zhang et al., 2001).

Although it is not the focus of this study, it is important to give a good representation of sulphate formation, since sulphate competes for the ammonia available to combine with nitric acid. Most models that represent a direct coupling of sulphur chemistry with photochemistry underestimate sulphate levels in winter in Europe. This feature can probably by explained by a lack of model calculated oxidants or missing reactions (Kasibhatla et al., 1997). Therefore, in addition to the gas phase reaction of $\mathrm{OH}$ with $\mathrm{SO}_{2}$ we represent additional oxidation pathways in clouds with a simple first order reaction constant $(R k)$, which is calculated as function of relative humidity $(\%)$ and cloud cover $(\varepsilon)$ :

$$
\begin{aligned}
R k= & 8.3 e-5^{*}\left(1+2^{*} \varepsilon\right)\left(\mathrm{min}^{-1}\right) \\
& \text { for } \mathrm{RH}<90 \% \\
R k= & 8.3 e-5^{*}\left(1+2^{*} \varepsilon\right)^{*}\left[1.0+0.1^{*}(\mathrm{RH}-90.0)\right]\left(\mathrm{min}^{-1}\right) \\
& \text { for } \mathrm{RH} \geq 90 \% .
\end{aligned}
$$

This parametrisation is similar to that used by Tarrason and Iversen (1998). It enhances the oxidation rate under cool and humid conditions. With cloud cover and relative humidity of $100 \%$ the associated time scale is approximately 2.5 days. Under humid conditions, the relative humidity in the model is frequently higher than $90 \%$ during the night. Model results using this parametrisation agree significantly 
better with observational data than results calculated using a reaction scheme that considers explicit cloud chemistry.

\subsection{Removal processes and boundary conditions}

The dry deposition of gases and aerosols is parametrised by the surface-atmosphere interaction model DEPAC (Erisman et al., 1994). From a $1.1 \times 1.1 \mathrm{~km}^{2}$ resolution land use database the fraction of surface in each grid cell covered by the land use classes used in DEPAC have been calculated (Nijenhuis and Groten, 1999). For each cell the deposition velocity is calculated weighting the surface fractions of every landuse class. Surface wetness and snow cover have a large effect on the deposition velocities for a number of species, especially $\mathrm{SO}_{2}$. Surface wetness is determined as function of the relative humidity at the surface. Wet deposition is calculated using simple coefficients for below cloud scavenging (de Leeuw et al., 1988). Since in-cloud scavenging is not accounted for, calculated concentrations in rainwater will probably be underestimated (see Sect. 3.3).

Boundary conditions for $\mathrm{O}_{3}, \mathrm{NO}_{\mathrm{x}}$ and VOC in LOTOS are obtained from the 2-D global Isaksen model (Roemer, 1995). For sulphate we use a boundary condition of $0.7 \mu \mathrm{g} / \mathrm{m}^{3}$ as deduced from measurements. Measurements show that sulphate is completely neutralized over remote areas in Europe (Kerminen et al., 2001). Therefore, we assume the imported sulphate to be fully neutralized by ammonium. Ammonium nitrate at the model boundaries was assumed to be zero. This assumption is probably valid for the west, north and south boundaries where the nitrate concentrations in air are very low or associated with sea salt and dust (Kerminen et al., 2001, Kouvarakis et al., 2002). At the eastern boundary, however, the assumed boundary conditions and, hence, the model results for both nitrate and sulphate are highly uncertain and we therefore decided to present results only west of $30^{\circ} \mathrm{E}$.

\section{Results and preliminary discussion}

In the following section we present modelled seasonal and annual aerosol distributions for the year 1995. Section 3.2 describes the formation of nitrate and in Sect. 3.3 a detailed comparison with available measured data is made. In our comparison we focus on the concentrations of nitrate, but also present supporting information on sulphate, ammonium and the aerosol precursors.

\subsection{Aerosol distributions}

In Fig. 3 the annual averaged fields of aerosol nitrate, sulphate, ammonium and their gaseous precursors are presented.

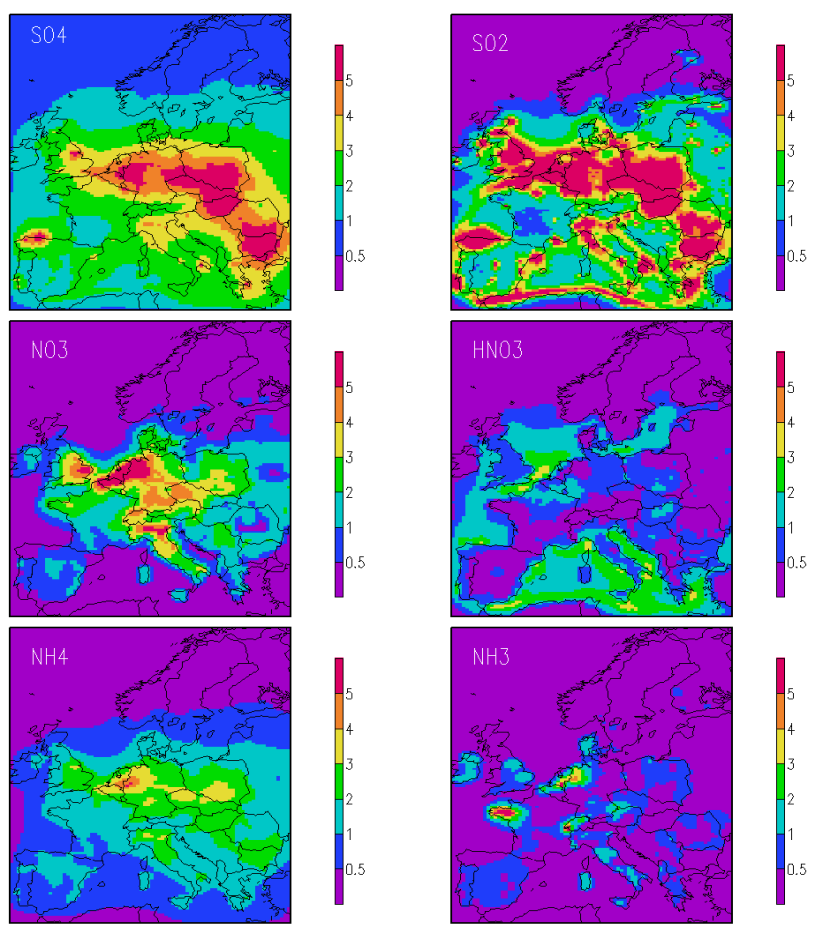

Fig. 3. Annual average concentrations $\left(\mu \mathrm{g} / \mathrm{m}^{3}\right)$ of inorganic aerosols and their precursor gases at measuring height.

\subsubsection{Nitrate}

Nitrate, in our model present as ammonium nitrate, is a continental phenomenon, since its concentration rapidly trails off from coast to open sea. Maximum nitrate concentrations are found in an area over The Netherlands, Belgium and north western Germany where modelled concentrations range between 5 and $8 \mu \mathrm{g} / \mathrm{m}^{3}$. Elevated concentrations can also be identified over northern Italy, UK, southern Germany and the Czech Republic, where the annual averaged concentrations exceed $4 \mu \mathrm{g} / \mathrm{m}^{3}$. These areas, incidentally, are characterized by high ammonia emissions. Over southern Europe nitrate concentrations do not exceed $2 \mu \mathrm{g} / \mathrm{m}^{3}$, except for northern Italy and a region over former Yugoslavia. Over most of Scandinavia annual average nitrate concentrations are calculated to be lower than $0.5 \mu \mathrm{g} / \mathrm{m}^{3}$, due to the low amounts of nitric acid formed there.

\subsubsection{Sulphate}

In case of sulphate a band of high concentrations, 3 to $7 \mu \mathrm{g} / \mathrm{m}^{3}$, is calculated over western Europe to the Balkans with maximum concentrations in Germany, Poland and southeastern Europe. Secondary maxima can be observed in northern Spain, central UK and the Po valley. In more remote regions the concentration ranges between 2 and $3 \mu \mathrm{g} / \mathrm{m}^{3}$. In northern Scandinavia the modelled concentrations are less than $1 \mu \mathrm{g} / \mathrm{m}^{3}$. 


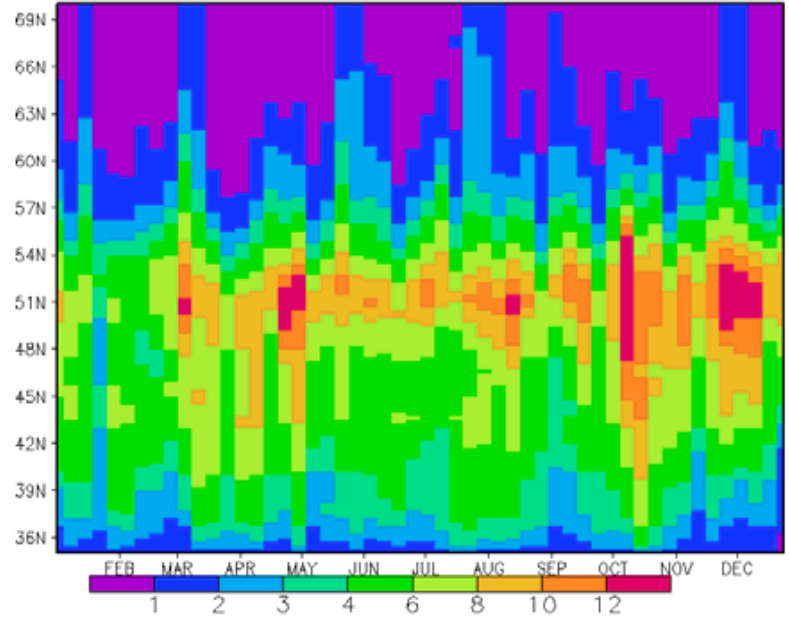

(a)

Fig. 4. Seasonal variation of (a) the $\mathrm{NO}_{3} /\left(\mathrm{NO}_{3}+\mathrm{SO}_{4}\right)$ ratio and (b) the total dry inorganic aerosol mass $\left(\mu \mathrm{g} / \mathrm{m}^{3}\right)$, averaged over $10^{\circ} \mathrm{W}$ to $30^{\circ} \mathrm{E}$ on a weekly basis.

\subsubsection{Nitrate to sulphate ratio}

To assess the contribution of nitrate we show the nitrate mass ratio $\left(\mathrm{NO}_{3} /\left[\mathrm{NO}_{3}+\mathrm{SO}_{4}\right]\right)$ in Fig. $4 \mathrm{a}$. A clear seasonal trend can be observed with the lowest contribution in summer. In this season nitrate is confined to western Europe. Large nitrate contributions can be identified over The Netherlands, northern Italy and UK. The ratio ranges between 10 and 30\% for the latitude band between $46^{\circ} \mathrm{N}$ and $56^{\circ} \mathrm{N}$. The ambient conditions, i.e. high temperature and low relative humidity, in eastern and southern Europe do not favor ammonium nitrate formation. In summary, in summer concentrations of sulphate are much higher than those of nitrate in most regions.

In the winter, spring and fall nitrate shows a different behavior than in the summer, despite the fact that the concentrations of sulphate are marginally different in the various seasons. In the mentioned seasons the nitrate concentration field shows a large area of high nitrate concentrations over western and central Europe. High concentrations during winter and early spring are calculated in the Po valley, where they are almost everywhere above $7 \mu \mathrm{g} / \mathrm{m}^{3}$. The contribution of nitrate ranges between 30 and $60 \%$ between 40 to $60^{\circ} \mathrm{N}$. In western Europe the nitrate concentrations exceed those of sulphate, whereas they are slightly lower than those of sulphate in eastern Europe. The higher nitrate concentrations as compared to the summer can be explained by the much higher stability of ammonium nitrate at low(er) ambient temperatures and higher relative humidities. The maximum contribution of nitrate occurs in spring, which coincides with the maximum ammonia emissions in this season.

\subsubsection{Total secondary inorganic mass}

In Fig. $4 \mathrm{~b}$ the weekly variation of the secondary inorganic mass, the sum of nitrate, sulphate and ammonium, over 1995 is shown as function of latitude. During 1995 maximum concentrations were found in autumn and in early winter, e.g. October to December. Also during spring the inorganic mass concentrations are slightly enhanced. Throughout the whole year the total inorganic mass is highest between $47^{\circ} \mathrm{N}$ and $54^{\circ} \mathrm{N}$, with concentrations exceeding $6 \mu \mathrm{g} / \mathrm{m}^{3}$ on average. Levels decrease strongly going from the European continent towards southern Scandinavia. In the south the gradient trailing off from the central maximum is less steep, which is in line with the higher emissions and population density there as compared to northern Europe.

\subsubsection{Precursor gases}

At continental regions the annual average nitric acid concentrations are mainly below $1.0 \mu \mathrm{g} / \mathrm{m}^{3}$, see Fig. 3. Over sea the concentrations are much higher than those over land. The ship tracks, in which large amounts of $\mathrm{NO}_{\mathrm{x}}$ are emitted, are visible in the calculated nitric acid fields. As noted before, in these regions in reality this nitric acid may be associated with sea salt. In winter computed concentrations of nitric acid are much lower then those of nitrate. In summer, only in north western Europe nitric acid concentrations are well below those of nitrate. In other areas they are higher or comparable to those of aerosol nitrate.

Due to the short atmospheric lifetime of ammonia its concentration field strongly resembles its emission distribution (Fig. 3). Maximum concentrations occur in the areas with the highest emissions, such as The Netherlands, southern UK and the Po-valley. Only in these areas mixing layer averaged annual concentrations of more than $1 \mu \mathrm{g} / \mathrm{m}^{3}$ are calculated. Outside the source areas the ammonia concentrations decline rapidly. 
Table 2. Comparison between observed and simulated concentrations $\left(\mu \mathrm{g} / \mathrm{m}^{3}\right)$ of aerosol nitrate for 1995. Methods are denoted by: $\mathrm{DF}=$ Denuder Filter pack, $\mathrm{CF}=$ Cellulose Filter and $\mathrm{IF}=$ Inert Filter.

\begin{tabular}{lcccccl}
\hline Station & Lon & Lat & Method & Obs & Sim & Reference \\
\hline Melpitz & 12.9 & 51.5 & IF-Quartz & 3.9 & 3.3 & Muller et al. (1998) \\
Muncheberg & 14.1 & 52.5 & DF & 2.2 & 3.3 & Zimmerling et al. (2001) \\
De Zilk & 4.5 & 52.3 & DF & 4.0 & 3.6 & RIVM (1997) \\
Wieringerwerf & 5.0 & 52.8 & DF & 4.5 & 3.2 & RIVM (1997) \\
Bilthoven & 5.2 & 52.1 & DF & 4.9 & 6.2 & RIVM (1997) \\
Kolummerwaard & 5.3 & 53.3 & DF & 4.5 & 3.7 & RIVM (1997) \\
Vreedepeel & 5.9 & 51.5 & DF & 4.6 & 7.9 & RIVM (1997) \\
Monte Libretti & 12.6 & 42.1 & DF & 2.8 & 3.3 & EMEP (1997) \\
Wallisellen* & 8.6 & 47.4 & DF & 3.7 & 4.7 & Thoni et al. (2000) \\
\hline
\end{tabular}

* Data for May-December. Not included in statistical analysis due to 2 weekly sampling at the site.

\subsection{Nitric acid formation}

Nitric acid/nitrate is formed via homogeneous gas phase oxidation and heterogeneous reactions. Since photochemistry is inefficient during winter the high ammonium nitrate concentrations modelled for the winter can only be explained by 1) a longer effective lifetime of nitrate in winter as compared to the summer and 2) a substantial production of nitric acid via the heterogeneous pathway. The longer life time of (total) nitrate in winter can be explained by the higher stability of ammonium nitrate in winter, which causes a higher portion of the nitrate to partition to the aerosol, which has a longer lifetime than nitric acid against deposition. In Fig. 5 the relative contribution of the heterogeneous hydrolysis of $\mathrm{N}_{2} \mathrm{O}_{5}$ to the total nitric acid production is shown throughout the year. In the model domain more than $50 \%$ of the nitric acid in winter is formed heterogeneously, especially in the high latitude regions where the days are short and light intensity is low. Photochemical formation is more important during summer, although heterogeneous formation of nitric acid is still significant $(\sim 20 \%)$. In general, the relative contribution of the heterogeneous reaction increases towards the north, which can be understood from competing effects of temperature, light and $\mathrm{OH}$ radical concentrations. The only exception occurs during mid summer when at high latitudes the nights are very short and the $\mathrm{OH}$ reaction becomes relatively more important again with increasing latitude.

\subsection{Comparison with measured data}

In this section we compare the model results with observations. Verification of model results is only possible when reliable data are available.

\subsubsection{Availability of measurements}

For sulphate and sulphur dioxide a large database of data exists, e.g. EMEP (1999). Measuring sulphate seems a straight-

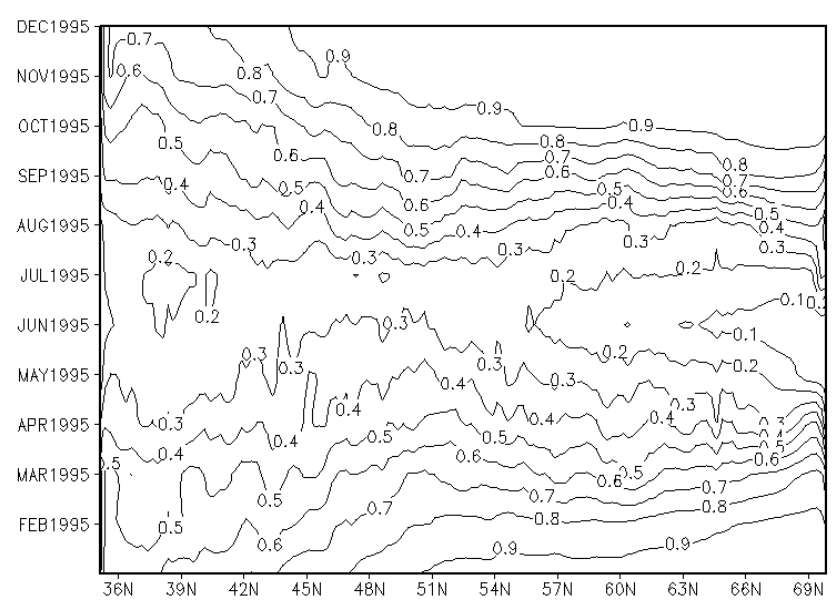

Fig. 5. The ratio of the heterogeneous to total nitric acid formation as function of latitude (averaged over $10^{\circ} \mathrm{W}$ to $30^{\circ} \mathrm{E}$ ) and season.

forward procedure. Measurements of particulate nitrate are sparser and moreover most methods are not reliable because of artefacts associated with the volatility of ammonium nitrate, and the reactivity of nitric acid. Schaap et al. (2002a) made a compilation of available aerosol nitrate measurements in Europe and critically assessed their quality. Shortly, reliable data are only obtained with devices that remove nitric acid prior to aerosol sampling and stabilize the collected ammonium nitrate against evaporation, e.g. denuder filter combinations. Field campaigns in Europe indicate that evaporation from quartz filters is significant at temperatures higher than $20^{\circ} \mathrm{C}$ (Schaap et al., 2004). Hence, the obtained data for nitrate (and ammonium) are likely to represent lower limits. Teflon filters are more vulnerable to evaporation losses (Eatough et al., 1988; Hering and Cass, 1999) and data obtained with these filters have not been used here. Positive artefacts occur by adsorption of nitric acid on the filter and data from cellulose filters are thus interpreted as total nitrate, the sum of aerosol nitrate and gaseous nitric acid. In winter 
Table 3. Comparison between observed and simulated concentrations $\left(\mu \mathrm{g} / \mathrm{m}^{3}\right)$ of aerosol ammonium for 1995. Methods are denoted by: $\mathrm{DF}=$ Denuder Filter pack, $\mathrm{CF}=$ Cellulose Filter and $\mathrm{IF}=$ Inert Filter.

\begin{tabular}{lcccccl}
\hline Station & Lon & Lat & Method & Obs & Sim & Reference \\
\hline Melpitz & 12.9 & 51.5 & IF-Quartz & 3.0 & 2.8 & Muller et al. (1998) \\
Muncheberg & 14.1 & 52.5 & DF & 3.0 & 2.8 & Zimmerling et al. (2001) \\
Ispra & 8.5 & 45.8 & CF & 2.9 & 2.5 & EMEP (1997) \\
Preila & 21.1 & 55.4 & CF & 0.6 & 1.3 & EMEP (1997) \\
Rucava & 21.2 & 55.2 & CF & 1.3 & 1.0 & EMEP (1997) \\
Zoseni & 25.9 & 57.1 & CF & 1.1 & 0.9 & EMEP (1997) \\
De Zilk & 4.5 & 52.3 & DF & 2.2 & 2.7 & RIVM (1997) \\
Wieringerwerf & 5.0 & 52.8 & DF & 2.7 & 2.4 & RIVM (1997) \\
Bilthoven & 5.2 & 52.1 & DF & 2.7 & 3.5 & RIVM (1997) \\
Kolummerwaard & 5.3 & 53.3 & DF & 2.3 & 2.4 & RIVM (1997) \\
Vreedepeel & 5.9 & 51.5 & DF & 2.5 & 4.3 & RIVM (1997) \\
Jarczew & 22.0 & 51.3 & CF & 2.5 & 2.7 & EMEP (1997) \\
Diabla Gora & 17.5 & 54.8 & CF & 1.7 & 1.6 & EMEP (1997) \\
Wallisellen* & 8.6 & 47.4 & DF & 3.1 & 2.5 & Thoni et al. (2000) \\
\hline
\end{tabular}

* Data for May-December. Not included in statistical analysis due to 2 weekly sampling at the site.

Table 4. Statistics on model to observation comparison. The comparison between averaged modelled and measured concentrations for individual sites is shown in Fig. 6.

\begin{tabular}{lcccccc}
\hline & $\mathrm{SO}_{4}$ & $\mathrm{SO}_{2}$ & $\mathrm{NO}_{3}$ & $\mathrm{TNO}_{3}$ & $\mathrm{NH}_{4}$ & $\mathrm{TNH}_{4}$ \\
\hline aver(model)/aver(meas) & 0.92 & 1.10 & 1.10 & 0.81 & 1.08 & 0.88 \\
residual & 1.77 & 2.57 & 2.47 & 1.45 & 1.08 & 1.01 \\
RMSE & 2.60 & 4.15 & 3.57 & 2.31 & 1.54 & 1.50 \\
$\sigma$ (model/meas) & 0.99 & 0.69 & 0.91 & 0.85 & 0.86 & 0.66 \\
correlation coeff & 0.60 & 0.48 & 0.58 & 0.52 & 0.62 & 0.58 \\
\% within factor 2 & 65.4 & 50.3 & 56.9 & 57.6 & 68.8 & 68.3 \\
number of sites & 42 & 39 & 9 & 21 & 13 & 18 \\
\hline
\end{tabular}

both evaporation and adsorption of nitric acid is thought to be small due to low ambient temperatures and small nitric acid concentrations. Hence, summertime data were found to be more uncertain than those acquired during winter. Most of the stations measuring total nitrate are located along a coastline. Aerosol nitrate data are mostly found at continental sites. Mountain stations have been excluded for the model to measurement comparison because 1) the orography and therefore the representation of the mixing layer height in these areas are strongly parameterised in the model which makes it difficult to correctly assess in which model layer the station is located, 2) for the higher stations the boundary conditions obscure the comparison and 3 ) the measurements may be strongly influenced by sub-grid meteorological phenomena.
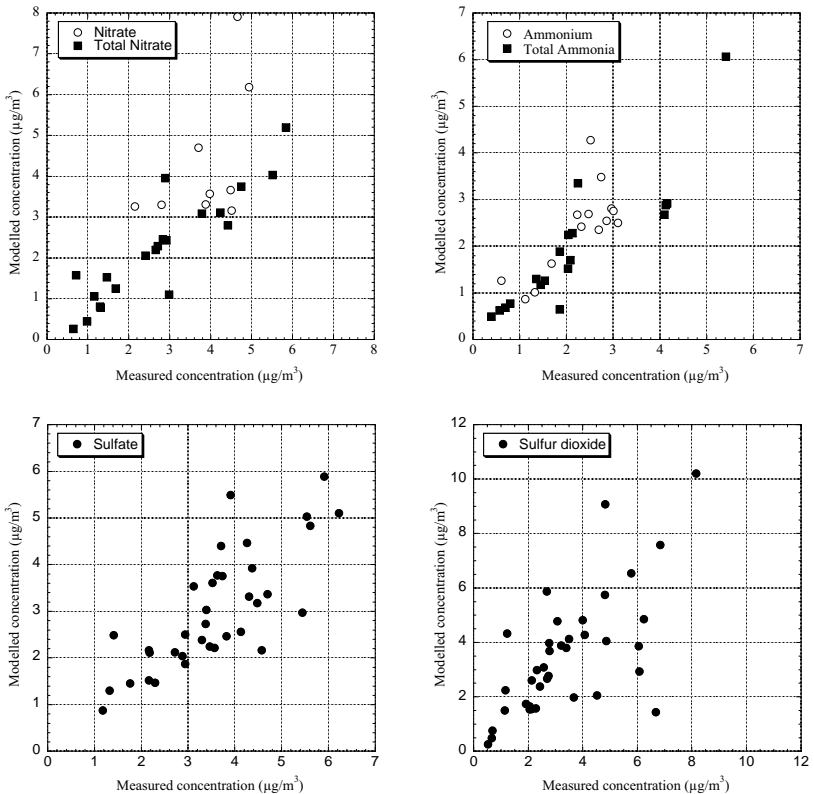

Fig. 6. Comparison of simulated and measured annual averaged concentrations of the inorganic aerosol components.

\subsubsection{Comparison of modelled and measured aerosol}

The modelled annual average concentrations of the inorganic aerosol species are compared to measured data in Fig. 6 . The comparison for nitrate and ammonium is presented for each station in Tables 2 and 3. In Table 4 we show a number of statistical parameters, calculated on a daily basis. Besides the ratio between the modelled and measured average values we show the average correlation coefficient, the residual, 

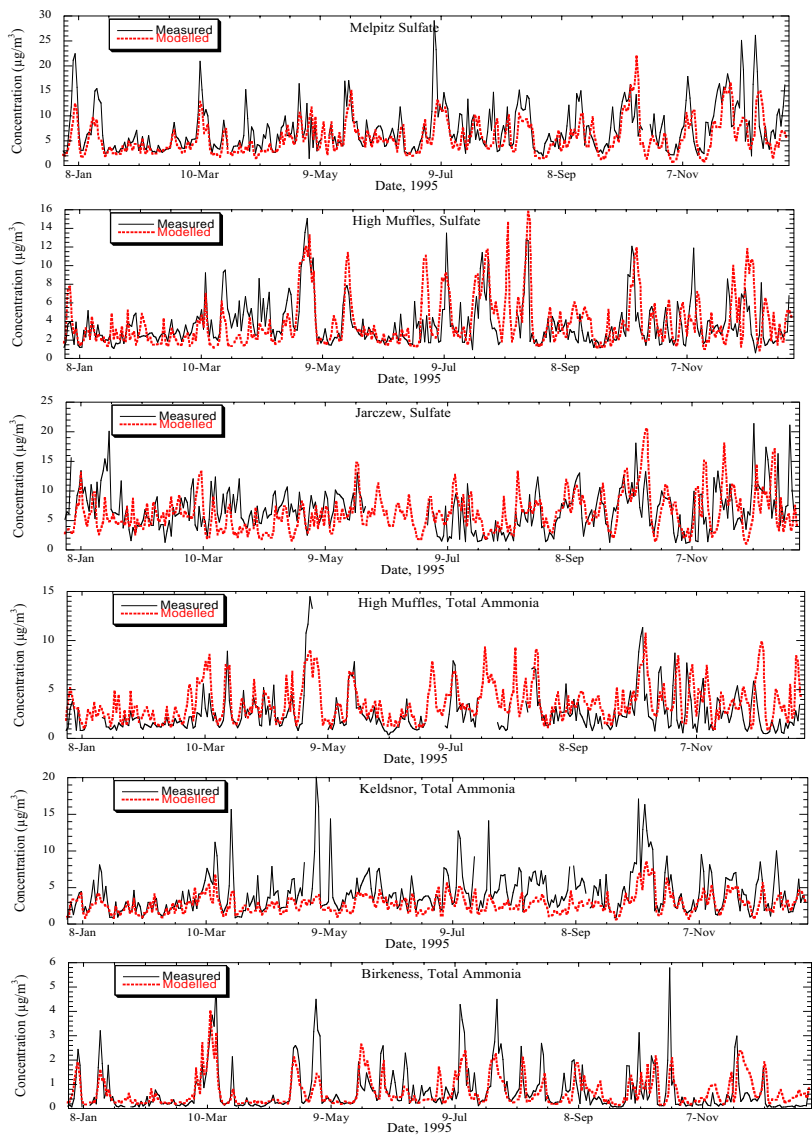

Fig. 7. Modelled and measured time series of sulphate and total ammonia over 1995.

the root mean square of the difference (RMSE) and the fraction of modelled concentrations that are within a factor of two of the measured values. The ability of the model to predict the amplitude of the daily variations is analysed using the normalised ratio of standard deviations of the mean concentrations. For a detailed description of the statistical parameters used we refer to the Appendix. A selection of stations, chosen to represent different regions in Europe, was made for which time series of the model to measurement comparison are shown in Figs. 7 to 10.

Nitrate

On average the model simulates slightly higher (10\%) aerosol nitrate concentrations than those measured. However, for single stations the agreement is not as good as indicated by the average RMSE of $3.57 \mu \mathrm{g} / \mathrm{m}^{3}$. The RMSE for nitrate is higher than for sulphate, indicating that the simulated nitrate data deviate more from the measured data. Likewise a smaller fraction (57 vs. $65 \%$ ) of the modelled values are within a factor of 2 of the measured data. The comparison is biased towards measurements obtained in
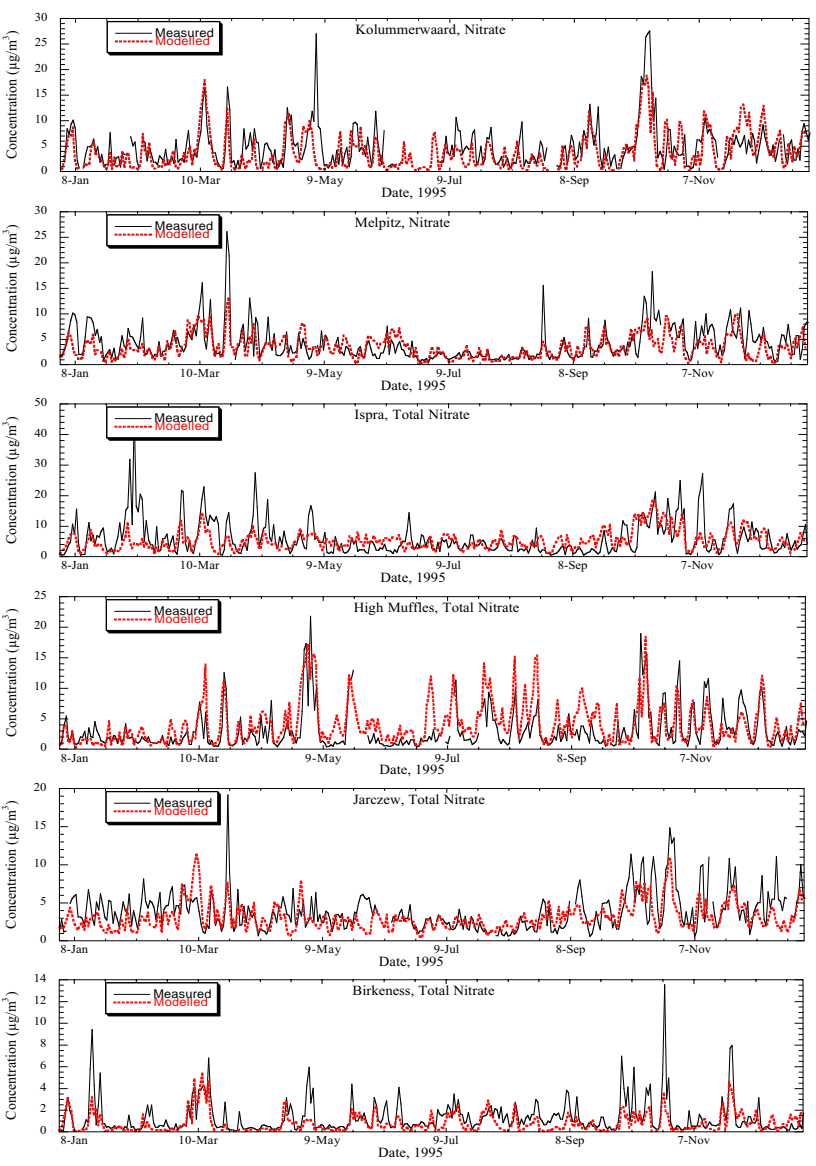

Fig. 8. Modelled and measured time series of nitrate and total nitrate over 1995.

The Netherlands, since 5 out of 9 stations are located there (see Table 2). The measured data do not show a significant gradient over The Netherlands, whereas the model simulates the highest concentrations inland and lowest at the coast. The (different) seasonal variations in The Netherlands and eastern Germany are well reproduced by the model (compare Figs. 8a and b). In southern Europe only at Monte Libretti, near Rome, aerosol nitrate is measured routinely. Although modelled and measured data compare favourably, strong conclusions on model performance in this part of Europe can not be drawn on basis of one station.

\section{Sulphate}

On average simulated and measured sulphate concentrations agree fairly well (ratio=0.92). Also, the time series show that the model is able to simulate the general behaviour of the sulphate in the atmosphere surprisingly well $(r=0.6)$. The overall variability of the modelled concentrations compares favourably, albeit that the model does not always reproduce the amplitude of single events. Only, for the German EMEP stations we find the measured data to be 


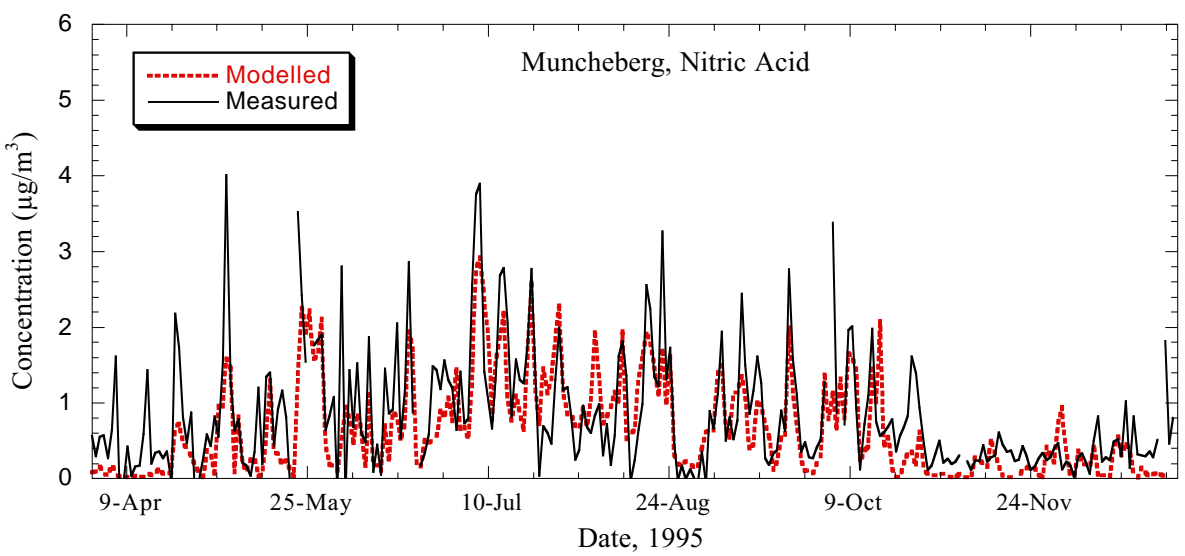

Fig. 9. Modelled and measured time series of nitric acid at Muncheberg, Germany (Measured data from Zimmerling et al., 2000).

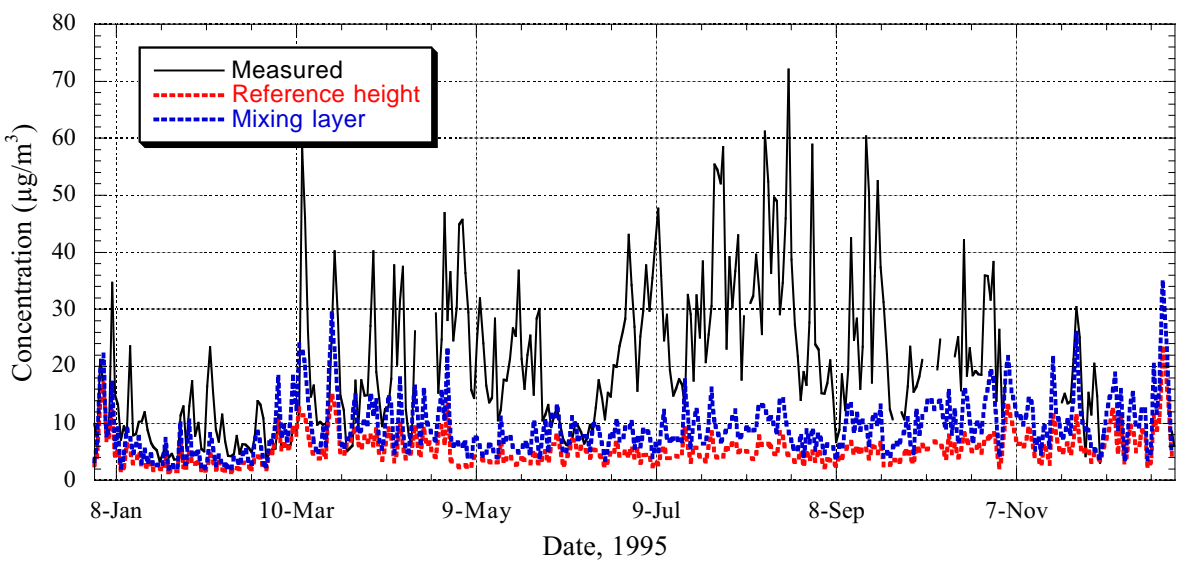

Fig. 10. Measured and modelled time series of ammonia at Vredepeel, the Netherlands, for measuring height and the mixing layer.

consistently lower than the modelled data. This behaviour has also been observed in a larger model intercomparison (Hass et al., 2003). They showed that the measurement data are systematically underestimating the actual concentrations and could exclude the influence of emissions being to low.

\section{Ammonium}

Aerosol nitrate and sulphate are associated with ammonium. In reality, this is only the case in air masses with a continental signature. Aerosol ammonium is mainly measured at continental stations and the computed ammonium data compare well with measured data. Moreover, on average the comparison for ammonium is better than for nitrate and sulphate, as indicated by the lower average residual (1.08), RMSE (1.54) and higher correlation coefficient (0.62). Underestimation and overestimation of (ammonium) sulphate appear to be somewhat balanced by (ammonium) nitrate. Overestimation and underestimation of ammonium are found at the same sites as for nitrate, compare Tables 3 and 4.
Total nitrate and total ammonia

Indirect information to verify simulated aerosol nitrate and ammonium concentrations is provided by measurements of total nitrate $\left(\mathrm{NO}_{3}+\mathrm{HNO}_{3}\right)$ and total ammonia $\left(\mathrm{NH}_{4}+\mathrm{NH}_{3}\right)$. The statistical parameters indicate that the simulated total nitrate and total ammonia levels are on average somewhat underestimated (19\% and 12\%, respectively). As for sulphate the model captures the daily variability in the measurements, although peak values are not always represented well. Moreover, under or overestimation of these measures are correlated. At High Muffles (GB14) total nitrate peaks are overestimated, which are correlated with an overestimation of total ammonia. On the other hand, at Birkeness (NO01) events with high nitrate and ammonium levels are accurately reproduced, but peak values are underestimated. The relative amplitude of modelled $\mathrm{TNH}_{3}$ is only $66 \%$ of that measured, which may be explained by the influence of primary emitted ammonia on spatial scales not represented by our model (see next section). 
Table 5. Comparison between modelled $\mathrm{HNO}_{3}$ concentrations $\left(\mu \mathrm{g} / \mathrm{m}^{3}\right)$ and those estimated by Schaap et al. $(2001,2002 \mathrm{a})$.

\begin{tabular}{lccc}
\hline Station & Country & Estimated & Modelled \\
\hline Keldsnor & DK & 0.4 & 0.8 \\
Anholt & DK & 0.4 & 0.9 \\
Tange & DK & 0.4 & 0.1 \\
Ulborg & DK & 0.4 & 0.2 \\
Fredriksborg & DK & 0.4 & 0.5 \\
Payerne & CH & 0.3 & 0.05 \\
Eskdalemuir & GB & 0.4 & 0.2 \\
High Muffles & GB & 0.4 & 0.2 \\
Leba & PL & 0.4 & 0.4 \\
Diabla Gora & PL & 0.4 & 0.2 \\
Jarczew & PL & 0.6 & 0.8 \\
Rucava & LV & 0.4 & 0.4 \\
Birkenes & NO & 0.2 & 0.4 \\
Skreadalen & NO & 0.2 & 0.2 \\
Osen & NO & 0.2 & 0.1 \\
Vavihill & SE & 0.4 & 0.2 \\
Roervik & SE & 0.4 & 0.8 \\
Aspvreten & SE & 0.4 & 0.4 \\
Uto & FI & 0.4 & 0.9 \\
Virolahti & FI & 0.4 & 0.2 \\
\hline
\end{tabular}

Ammonia

It is difficult to compare our model results for ammonia concentrations with measurements, since ammonia concentrations may strongly vary over horizontal distances of hundreds of meters and may have strong vertical gradients. An additional complication arises due to the model structure. Secondary components like nitric acid are removed at the ground and, therefore, their vertical distribution near the ground can be calculated form the layer averaged concentration using information on their deposition velocity. In contrast, due to surface emissions ammonia concentrations decline with height in their source areas (Erisman et al., 1988). As calculation of the concentrations at a reference height of two meter takes deposition processes into account but not emission, the calculated ammonia concentrations at $2 \mathrm{~m}$ in or nearby sources may be substantially underestimated. This feature is illustrated in Fig. 10 where the ammonia concentration at the site with the highest emission density in Europe, Vredepeel, is shown. There the computed mixing layer concentration is on average twice the concentration at $2 \mathrm{~m}$. The deviation between measurement and model is highest for the summer months when the mixing layer is thick. Similar behaviour is observed for total ammonia measurements in ammonia rich areas, see DK05 (Fig. 7e). For remote areas where there is a (large) net deposition the modelled concentration at $2 \mathrm{~m}$ are expected to be directly comparable to measured data. The data available
Table 6. Comparison between observed and modeled rain water concentrations.

\begin{tabular}{lcccc}
\hline & $\mathrm{mm}$ & Swet & NHwet & NOwet \\
\hline aver(model)/aver(meas) & 0.94 & 0.37 & 0.16 & 0.67 \\
residual & 4.56 & 0.73 & 0.91 & 0.69 \\
RMSE & 7.29 & 1.19 & 1.64 & 1.12 \\
$\sigma$ (model/meas) $^{*}$ & 0.78 & 0.51 & 1.32 & 1.46 \\
correlation coeff $_{\% \text { within factor 2 }}$ & 0.40 & 0.20 & 0.04 & 0.03 \\
& 37.15 & 33.36 & 7.09 & 36.85 \\
\hline
\end{tabular}

in these areas are total ammonium data only, which show lower modelled concentrations as compared to observations as discussed above.

Nitric acid

Only two stations, i.e. Müncheberg and Rome, had gaseous nitric acid measurements covering the whole year of 1995. The model to measurement comparison for Müncheberg (D) is shown in Fig. 9. Although the daily values are not always represented in detail, the correlation and variability on a daily basis as well as the seasonal variation compare reasonably well $(r=0.72)$, which also applies for Rome (I) $(r=0.71)$. Additional nitric acid data were compiled by Schaap et al. (2001), who estimated the nitric acid component of total nitrate concentrations north of the Alps. The estimates for the average nitric acid concentration during winter are shown in Table 5. These estimates show that average nitric acid concentrations are remarkably similar and below $0.5 \mu \mathrm{g} / \mathrm{m}^{3}$ throughout northern Europe. At inland locations the modelled and estimated concentrations agree generally within a factor of 2 . The simulated nitric acid concentrations for two stations located on small islands, Anholt (Dk) and Uto (F), show the largest deviations, more than a factor of 2, and are higher than the observed range of nitric acid levels evaluated by Schaap et al. (2001). It is much more difficult to evaluate the nitric acid concentrations in summer, since the measured data on nitric acid show higher variability than in winter. Nitric acid concentrations for campaigns at the same site during the same month in different years may vary a factor of 5 (Schaap et al., 2001). However, the maximum concentrations averaged over the duration of a campaign in summer is lower than $2 \mu \mathrm{g} / \mathrm{m}^{3}$, indicating that nitric acid concentrations averaged over a whole summer are not expected to exceed $2 \mu \mathrm{g} / \mathrm{m}^{3}$. This indicates that in coastal and marine areas in northern Europe the modelled nitric acid concentrations are overestimated (see Sect. 4). 


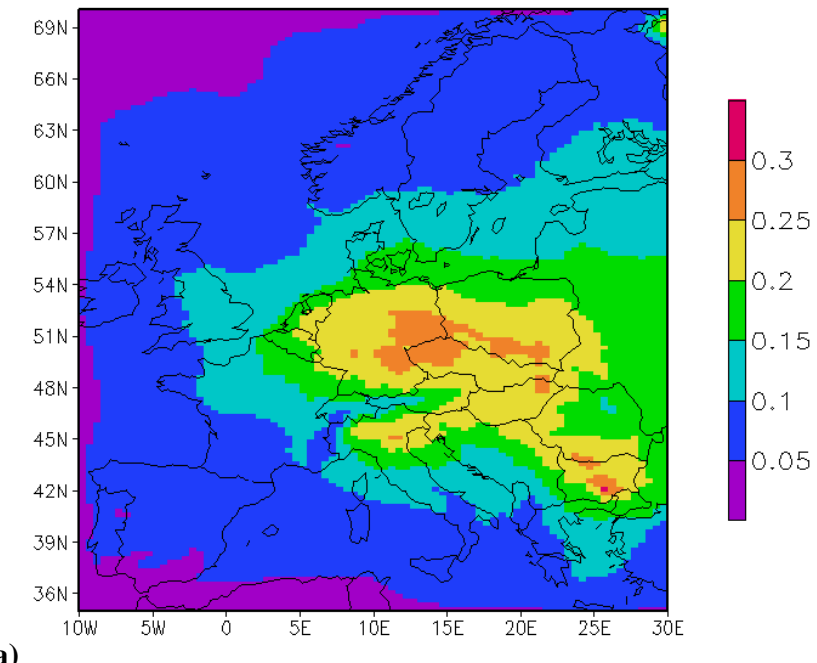

(b)

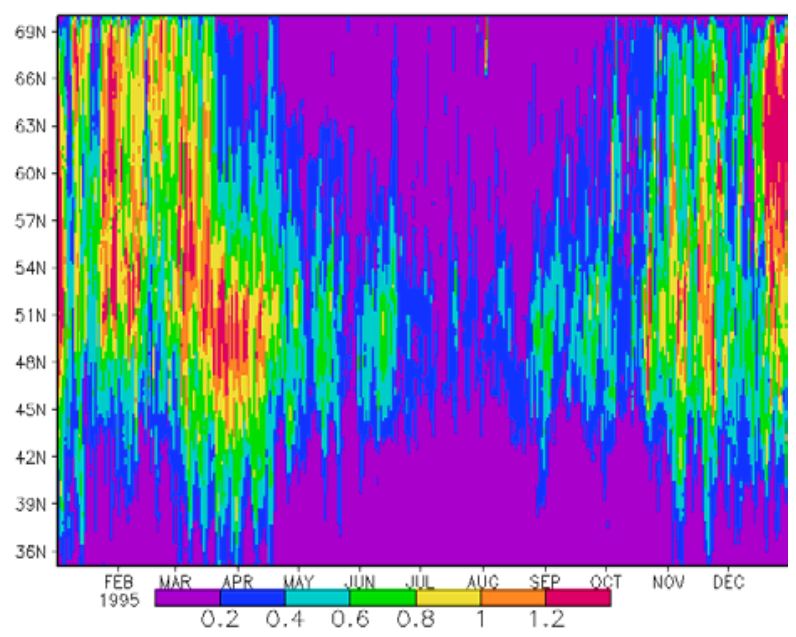

Fig. 11. (a) Annually averaged total AOD over Europe and (b) the nitrate to sulphate AOD ratio as function of latitude (averaged over $10^{\circ} \mathrm{W}$ to $30^{\circ} \mathrm{E}$ ) and season. Values represent noon values.

\section{Rainwater composition}

An important data set giving information on atmospheric concentrations of aerosols and its precursors is that of rainwater composition. In Table 6 the statistics from the model to measurement comparison are shown. On average the rain intensities derived from the meteorological input fields compare well with observations. However, the daily correlation is low (0.40) and the mean root mean square of the difference is large $(7.29 \mathrm{~mm})$, which indicates large variability. On average the modelled wet deposition underestimates the actual wet deposition by a factor of 2 or more for all components. Inspection of the measurements shows that the largest part of the deposition flux is due to a few rain events, which are not represented in the model. Part of the discrepancy may also be explained by the input data on rain, however, the total amount of rain is not very different from the measurements which leads to the conclusion that in our model the wet deposition is strongly underestimated. Additional causes will be discussed in Sect. 4.

\section{Aerosol optical depth}

The calculated aerosol nitrate burden over Europe contributes to the aerosol optical depth (AOD). AOD is the extinction of light due to particles in the atmosphere and thus provides a measure of the column integrated aerosol burden. From de modelled aerosol columns the AOD can also be derived, provided that correct assumptions on the physical and optical properties of aerosols are made. Hence, by comparing retrieved and modelled AOD values additional information on the performance of a model is obtained which is complementary to the validation of models with surface ob- servations. In addition, comparing the aerosol optical depth of separate aerosol species gives an indication of the relevance of these species for the direct aerosol effect. Below we present the modelled AOD for 1995. We compare the calculated AOD for August 1995 to that measured by the ATSR-II satellite in August 1997 (see Sect. 5).

Assuming that nitrate and sulphate have the same optical properties the AOD at $550 \mathrm{~nm}$ was computed from the modelled dry aerosol mass concentrations as described by Robles-Gonzales et al. (2003). To account for the variation of the aerosol scattering coefficient with relative humidity a growth factor obtained from humidity controlled nephelometry (Veefkind et al., 1996) was used in the AOD calculations. Effects due to hysteresis are not accounted for. In Fig. 11a we show the modelled annual average AOD due to secondary inorganic aerosols. We present values for 12:00 GMT, the time of overpass of the ATSR-II satellite, to compare with satellite observations (Robles-Gonzales et al., 2000, 2003) in Sect. 5. Annually averaged, modelled AOD at noon exceeds 0.25 in Rumania, Poland, the Czech Republic and the eastern part of Germany. Over the northwest and eastern Europe the AOD ranges between 0.15 and 0.25 . The AOD decreases towards the north and south west and becomes lower than 0.1 in Scandinavia, Ireland and the Iberian Peninsula.

The calculated ratio of the aerosol optical depth by nitrate to that by sulphate is given as function of latitude and time of year in Fig. 11b. Since nitrate concentrations are lowest around noon, the nitrate to sulphate ratio represents lower limits. The seasonal variation of nitrate is strongly visible in the calculated ratios. In July and August the ratio maximises at about $51^{\circ} \mathrm{N}$ but seldom exceeds $40 \%$, averaged for $10^{\circ} \mathrm{W}-30^{\circ} \mathrm{E}$. Inspection of the fields show that during these months only over The Netherlands and the Po Valley comparable concentrations and AOD's for nitrate and sulphate are 
computed. During the winter half year, October to March, the AOD by nitrate exceeds that of sulphate over a large part of Europe, indicating its large importance in that season.

\section{Discussion and conclusions}

In this paper aerosol calculations for the year 1995 are presented. The regional CTM used simulates the secondary inorganic aerosol, its precursors, as well as the oxidant concentrations over Europe. The model is able to simulate the general features of the secondary aerosol fields over Europe. Moreover, the model is able to simulate the daily variability reasonably well. Agreement between model and measurement is best for sulphate and ammonium. The performance of the model for nitrate and its precursors is not as good as indicated by higher residuals and RMSE. The comparison between the model and measurements shows higher deviations for nitrate than for sulphate and ammonium.

During the whole year nitrate concentrations are slightly overestimated by $10 \%$ on average, when compared to 9 stations. However, at single stations the difference may be much higher. The emissions, dispersion and reaction of ammonia are likely to be the most important cause of deviations between modelled and measured concentrations. The LOTOS model is not able to represent strong vertical gradients in the source regions. Therefore, too much ammonia may be "effectively" emitted to the atmosphere as explained in Sect. 2, which may result in an overestimation of ammonium nitrate as is observed for Bilthoven and Vredepeel, The Netherlands. The uncertainties in the representation of the ammonia sources and removal processes on the results are discussed in a separate publication (Schaap, 2003). That work concludes that the computed nitrate concentrations in the source areas are very sensitive to the total amount of ammonia emissions, the temporal distribution as well as the horizontal distribution of these emissions. Thus the details of the description of the ammonia sources and sinks are the largest source of uncertainty in the calculation of secondary nitrate aerosol (see also Schaap et al., 2002b). A higher vertical resolution in the mixing layer is needed to describe the vertical gradient of ammonia more accurately as well as a better understanding of (the temporal variability) ammonia emissions in Europe. On the other hand, the vertical resolution required in this context demands a very large computational burden as discussed by Asman (2001).

In addition to the representation of ammonia, uncertainties are present in the formation processes of nitric acid. In comparison to other photo-oxidant models LOTOS has relatively high $\mathrm{OH}$ concentrations (Roemer et al., 2003) which may cause a slightly too fast nitric acid formation in summer. Similarly, the heterogeneous formation rate of nitric acid may be inaccurate because we used reaction probability $\gamma$ of 0.05 for $\mathrm{N}_{2} \mathrm{O}_{5}$ hydrolysis, which is still under debate (Jacob, 2000; Mentel et al., 1999). Finally, other hetero- geneous $\left(\mathrm{NO}_{3}\right.$-radical) and homogeneous reactions (organic nitrates) of $\mathrm{NO}_{\mathrm{y}}$ may occur, which are not or very simplified included in our model.

Over the coastal and marine areas LOTOS predicts too high nitric acid concentrations. In the model, ammonia concentrations are decreasing from the continent towards the open sea, causing ammonium nitrate transported onto the ocean to evaporate. In addition, $\mathrm{NO}_{\mathrm{x}}$ is efficiently converted to nitric acid due to the high oxidant concentrations present over the sea. These phenomena were also found in observational data (Tamm and Schulz, 2003; Schulz et al., 1999). However, since LOTOS does not incorporate sea salt at the moment, it overestimates nitric acid which in reality resides in the coarse sea salt aerosol fraction (Tamm and Schulz, 2003). Inclusion of sea salt (and mineral dust) as a sink for nitric acid is therefore needed to describe the nitrate distribution in marine (and arid) areas more accurately.

In general, models have difficulties representing wet deposition correctly. For example, the wet deposition efficiency in de models participating in the COSAM study ranged over a factor of 4 (Roelofs et al., 2001). In LOTOS clouds are treated in a very simplified manner since the meteorological input only contains cloud cover. Underestimation of the concentrations of nitrate and other components in rainwater is most probably related to this issue. In-cloud scavenging, which is not represented in the model, accounts for a large part ( $\sim 60 \%)$ of the total wet deposition (Guttorp, 1986, zie cosam, GJ). We hypothesise that in our model a substantial part of the tracer mass, that would otherwise be removed by wet deposition, is transported through the model upper boundary in frontal activity. Unfortunately, we did not quantify the magnitude of this process. A better parametrisation for clouds and cloud processes should be included in the future. Experiments with faster scavenging rates show that the low correlation between the input and observed rain data causes the comparison between the modelled and measured concentrations in air to become much less favourably.

\subsection{Comparison with other studies}

Recent global modelling studies have provided more insight into the large scale ammonium nitrate formation. Adams et al. $(1999,2001)$ used off line calculated fields of nitric acid in combination with a sulphur chemistry model to calculate the partitioning of nitrate between the aerosol and gas phase. Their calculated nitrate concentrations were found to be too high on average in polluted continental areas. Improvements on the treatment of ammonia and the coupling with a full photo chemistry scheme were advised (Adams et al., 1999). The latter was taken up by Metzger et al. (2002a, b), who used the TM3 model to assess the global ammonium nitrate and sulphate distribution. In that study nitrate and total nitrate concentrations were highly overestimated by on average a factor of 2-3, with the highest overestimations during winter. The authors attributed these discrepancies to 1) the 
Table 7. Comparison between total AOD observed with ATSR-II and modeled by LOTOS and TM3 for several regions. For ATSRII a lower and upper estimate of the AOD is given (depending on treatment of missing values). For each model the AOD by nitrate is given between brackets.

\begin{tabular}{lcccc}
\hline & $\begin{array}{c}\text { ATSR-II } \\
1997\end{array}$ & $\begin{array}{c}\text { LOTOS } \\
1995\end{array}$ & $\begin{array}{c}\text { LOTOS } \\
1997\end{array}$ & $\begin{array}{c}\text { TM3_2.5 } \times 2.5 \\
1997\end{array}$ \\
\hline Europe & $0.21-0.28$ & $0.11(0.02)$ & $0.11(0.02)$ & $0.05(0.01)$ \\
Northern EU & $0.25-0.31$ & $0.13(0.02)$ & $0.14(0.04)$ & $0.06(0.01)$ \\
NW EU & $0.32-0.36$ & $0.16(0.03)$ & $0.19(0.06)$ & $0.09(0.02)$ \\
Central EU & $0.34-0.36$ & $0.20(0.05)$ & $0.21(0.07)$ & $0.08(0.02)$ \\
Reference* $^{\text {RG2000 }}$ & this study & RG2003 & J2001 \\
\hline
\end{tabular}

* RG2002=Robles-Gonzalez et al. (2000); RG2003=RoblesGonzalez et al. (2003); J2001=Jeuken et al. (2001).

underestimation of sulphate concentrations during winter, 2) the uncertainties in the representation of the ammonia cycle and 3) a too stable planetary boundary layer. Interestingly, they also showed that their modelled nitrate burdens increased with increasing model resolution.

Compared to Metzger et al. (2002b), our results are not only closer to the observations for nitrate but also for sulphate during winter. As noted before, our simple $\mathrm{SO}_{2}$ cloud oxidation scheme gives better results as compared to more detailed schemes. However, also the much higher resolution of the model specifically in respect to the ammonia emissions may explain a considerable part of the differences. Given the short lifetime of the species involved and the gradients in the ammonia emissions the equilibrium calculations are performed on a more appropriate spatial scale than in a global model with a horizontal resolution of several degrees. As a result, in contrast to Metzger et al. (2002b) our model does not show a large nitrate overestimation.

In Europe, the EMEP model (Tsyro, 2003) simulates nitrate on spatial and temporal scales similar to our model. Other regional model studies of nitrate formation are confined to episodes (Riemer et al., 2003) or the growing season, April-September (Hass et al., 2003). In the framework of a larger model intercomparison, results from an earlier version of our model were compared to those of several other models with different complexity. Differences between the models were large with a tendency to overestimate nitrate levels. Inspection of the results obtained by EMEP (Tsyro, 2003) shows that these fall within the range of the models participating in the comparison. The differences illustrate the complex nature of nitrate modelling and the associated uncertainties. A large effort is required to better describe the processes involving nitrate formation in the atmosphere.

The results shown in this study are obtained with a new model tool to describe the inorganic aerosol distribution over Europe. Unfortunately, it is inherently difficult to measure the semi volatile ammonium nitrate. Hence, we could verify our results only with a small set of measurements. More reliable data sets on $\mathrm{NO}_{3} / \mathrm{HNO}_{3}$ and $\mathrm{NH}_{3} / \mathrm{NH}_{4}$ are urgently needed to test model results. Moreover, high resolution data are needed to test the diurnal variation of nitrate and its precursors, equilibrium calculations and nitric acid formation. Regions of interest would be UK, The Netherlands, south western France, the Po valley, central Poland, south eastern Europe and southern Sweden. Given the strong gradients in ammonia levels, both vertical and horizontal, measurements on towers may be very useful to arrive at more spatial representative and mixed layer averaged properties.

\subsection{AOD}

Verification of modelled AOD is hampered by data availability, especially over land. An extensive comparison between modelled AOD from sulphate and nitrate for August 1997 and satellite observations is presented in Robles-Gonzales et al. (2003) and Jeuken et al. (2001), who used LOTOS and TM3, respectively. Our results for August 1995 are compared to these studies in Table 7.

The average calculated AOD with LOTOS for August 1995 is remarkably close to that for august 1997 by RoblezGonzalez et al. (2003). Only in northwestern Europe our previous calculations show a somewhat higher AOD, which can be fully attributed to differences in the calculated nitrate levels there (see Table 7). The LOTOS calculations for August 1997 show a more pronounced overestimation of nitrate levels over the Netherlands than the calculations for 1995 . Jeuken et al. (2001) addressed the AOD due to ammonium sulphate and nitrate with TM3, using similar emissions (for Europe) and a $2.5 \times 2.5^{\circ}$ resolution. The AOD calculated by LOTOS is systematically higher for both sulphate and nitrate. For example in central Europe Jeuken et al. (2001) calculated an average AOD of 0.08 , which can be compared to LOTOS $(0.20)$ and measurements $(0.35)$, illustrating the large differences between LOTOS and TM3 calculations. These differences originate from very different model approaches used by these models. Most important causes probably originate from the different horizontal resolutions (and its impact on ammonia levels) and the deposition and boundary layer parameterisations. A plausible explanation of the underestimation of total measured AOD in both LOTOS and TM3 is the absence of carbonaceous, sea salt and mineral dust aerosols in the models.

All studies show low AOD due to nitrate compared to that of sulphate for most of Europe in August. Only in north western Europe modelled nitrate contributed significantly to AOD. Moreover, regionally over the Netherlands comparable contributions of nitrate and sulphate to AOD were calculated, which are in line with the local observational evidence for the importance of nitrate there (Ten Brink et al., 1997). However, our results for 1995 indicate that these conclusions for August can not be extrapolated to other seasons, when the contribution of nitrate to AOD is significantly higher over 
continental Europe. A longer time series of AOD over Europe is needed to assess the contribution of nitrate and sulphate to AOD in these seasons. We plan to use ATSR2 data for the full year of 2000 for this purpose.

The aerosol optical depth calculations performed here can be used to assess the radiative forcing of nitrate and sulphate over Europe. A separate paper on the hour by hour radiative forcing calculations is under preparation. The forcing for nitrate over continental Europe was found to be roughly $50 \%$ that of sulphate in winter.

\subsection{Concluding remarks}

- We developed a model tool of intermediate complexity that is able to simulate the ammonium nitrate and sulphate concentrations over Europe on a daily basis.

- Nitrate concentrations show a significant seasonal cycle with lowest concentrations in summer and highest concentrations in winter and early spring.

- Except for the summer nitrate levels are comparable to those of sulphate for large parts of Europe.

- Heterogeneous chemistry plays an important role in the formation of nitric acid and aerosol nitrate.

- The description of the ammonia sources and sinks is the largest source of uncertainty in the calculation of secondary nitrate aerosol.

- Sea salt should be included in the model to simulate nitrate partitioning in marine areas correctly.

- The contribution of nitrate to aerosol optical depth over Europe is significant as compared to sulphate, especially during winter and spring.

\section{Appendix A: Statistical parameters}

For the definition of the statistical parameters used for the comparison between modelled $(M)$ and observed $(O)$ data we follow the definition by Hass et al. (2003). The comparison is based on pairs of modelled and measured data for a number of stations $(S)$ with available data for 1995 . The number of days is given by $D$, whereas $d$ and $s$ represent the day and station number, respectively.

The ratio of model results $M_{s, d}$ and results from observations $O_{s, d}$ is defined as:

Ratio $=\frac{\sum_{s=1}^{S} \sum_{d=1}^{D} M_{s, d}}{\sum_{s=1}^{S} \sum_{d=1}^{D} O_{s, d}}=\frac{\bar{M}}{\bar{O}}$.
The residual is the sum of the absolute deviations of model results and results from observations:

residual $=\frac{1}{S} \sum_{s=1}^{S} \frac{1}{D} \sum_{d=1}^{D}\left|M_{s, d}-O_{s, d}\right|$.

The root mean square error is defined as:

$\mathrm{RMSE}=\frac{1}{S} \sum_{s=1}^{S} \sqrt{\frac{1}{D} \sum_{d=1}^{D}\left(M_{s, d}-O_{s, d}\right)^{2}}$.

The normalized ratio of standard deviation (given in the tables as $\sigma$ (model/meas)) is

$\sigma^{*}=\frac{1}{S} \sum_{1}^{S} \frac{\overline{O_{s}}}{\overline{M_{S}}} * \frac{\sigma_{s, M}}{\sigma_{s, O}}$

with the standard deviation

$\sigma_{s, O}=\sqrt{\frac{1}{D} \sum_{1}^{D}\left(O_{s, d}-\overline{O_{s}}\right)}$

and the observed mean at a station $s$

$\overline{O_{s}}=\frac{1}{D} \sum_{1}^{D} O_{s, d}$

and a similar definition for the modelled mean. The average correlation coefficient rho is defined as

$\rho=\frac{1}{S} \sum_{S=1}^{S} \rho_{S}$

using the correlation in time at the individual stations

$\rho_{s}=\frac{\sum_{d=1}^{D}\left(O_{s, d}-\overline{O_{s}}\right)\left(M_{s, d}-\overline{M_{S}}\right)}{\sigma_{s, O} * \sigma_{s, M}}$.

The percentage within a factor of 2 is given as the percentage of days where

$0.5 \leq \frac{M_{s, d}}{O_{s, d}} \leq 2$. 
Edited by: J. Brandt

\section{References}

Adams, P. J., Seinfeld, J. H., and Koch, D. M.: Global concentrations of tropospheric sulphate, nitrate, and ammonium aerosol simulated in a general circulation model, J. Geophys. Res., 104, D11, 13 791-13 823, 1999.

Adams, P. J., Seinfeld, J. H., Koch, D. M., Mickley, L., and Jacob, D.: General circulation model assessment of direct radiative forcing by the sulphate-nitrate-ammonium-water inorganic aerosol system, J. Geophys. Res., 102, D1, 1097-1111, 2001.

Ansari, A. S. and Pandis, S. N.: Responce of Inorganic PM to Precursor Concentrations, Environ. Sci. Technol., 32, 2706-2714, 1998.

Asman, W. A. H.: Factors influencing local dry deposition of gases with special reference to ammonia, Atmos. Environ., 32, 415421, 1998.

Asman, W. A. H.: Modelling the atmospheric transport and deposition of ammonia and ammonium: an overview with special reference to Denmark, Atmos. Environ., 35, 1969-1983, 2001.

Asman, W. A. H. and Janssen, A. J.: A long-range transport model for ammonia and ammonium for Europe, Atmos. Environ., 21, 2099-2119, 1987.

Basset, M. and Seinfeld, J. H.: Atmospheric equilibrium model of sulphate and nitrate aerosols, Atmos. Environ., 17, 2237-2252, 1983.

Bogaard, A. and Duyzer, J.: Een vergelijking tussen resultaten van metingen en berekeningen van de concentratie van ammoniak in de buienlucht op een schaal kleiner dan5 kilometer, TNO-report, TNO-MEP-R97/423, Apeldoorn, The Netherlands, 1997.

Builtjes, P. J. H.: The LOTOS - Long Term Ozone Simulation - project, Summary report, TNO-report, TNO-MW-R92/240, 1992.

Builtjes, P. J. H., van Loon, M., Schaap, M., Teeuwisse, S., Visschedijnk, A. J. H., and Bloos, J. P.: Project on the modelling and verification of ozone reduction strategies: contribution of TNO-MEP, TNO-report, TNO-MEP-R2003/166, Apeldoorn, The Netherlands, 2003.

Charlson, R. J., Schwartz, S. E., Hales, J. M., Cess, R. D., Coakley, J. A., Hansen, J. E., and Hofmann, D. J.: Climate forcing by anthropogenic aerosols, Science, 255, 423-430, 1992.

De Leeuw, F. A. A. M., van Rheineck Leyssius, H. J., van den Hout, K. D., Diederen, H. S. M. A., Berens, M., and Asman, W. A. H.: RIVM Report 228471004, National Institute of Public Health and the Environment, Bilthoven, The Netherlands, 1988.

Dentener, F. J. and Crutzen, P. J.: Reaction of $\mathrm{N}_{2} \mathrm{O}_{5}$ on tropospheric aerosols: Impact on the global distributions of $\mathrm{NO}_{\mathrm{x}}, \mathrm{O}_{3}$, and $\mathrm{OH}$, J. Geophys. Res., 98, 7149-7163, 1993.

Dentener, F. J. and Crutzen, P. J.: A three-dimensional model of the global ammonia cycle, J. Atmos. Chem., 19, 331-369, 1994.

Eatough, N. L., McGregor, S., Lewis, E. A., Eatough, D. J., Huang, A. A., and Ellis, E. C.: Comparison of sic denuder methods and a filter pack for the collection of ambient $\mathrm{HNO}_{3}(\mathrm{~g}), \mathrm{HNO}_{2}(\mathrm{~g})$ and $\mathrm{SO}_{2}$ (g) in the 1985 NSMC study, Atmos. Environ., 22, 16011618, 1988.

EMEP: Data report 1995, Part 1: Annual summaries, EMEP/CCCReport 4/97, NILU, Oslo, Norway, 1997.
EMEP: Data quality 1997, quality assurance, and field comparisons, EMEP/CCC-Report 6/99, NILU, Oslo, Norway, 1999.

EMEP: http://www.emep.int, 2002.

Erisman, J. W., Vermetten, A. W. M., Asman, W. A. H., WaijersIjpelaan, A., and Slanina, J.: Vertical distribution of gases and aerosols, the behavior of ammonia and related compounds in the lower atmosphere, Atmos. Environ., 22, 1153-1160, 1988.

Erisman, J. W., van Pul, A., and Wyers, P.: Parametrization of surface-resistance for the quantification of atmospheric deposition of acidifying pollutants and ozone, Atmos. Environ., 28, 2595-2607, 1994.

Guttorp, P.: Models for transportation and deposition of atmospheric pollutants, University of Washington, Seattle, http: //www.stat.washington.edu/peter/498/transport/section3_5.html, 1986.

Hass, H., Builtjes, P. J. H., Simpson, D., and Stern, R.: Comparison of model results obtained with several European air quality models, Atmos. Environ., 31, 3259-3297, 1997.

Hass, H., van Loon, M., Kessler, C., Stern, R., Matthijsen, J., Sauter, F., Zlatev, Z., Langner, J., Foltescu, V., and Schaap, M.: Aerosol Modelling: Results and Intercomparison from European Regional-scale Modelling Systems, Eurotrac publication in press, Eurotrac-ISS, Garmisch Partenkirchen, Germany, 2003.

Haywood, J. M. and Boucher, O.: Estimates of the direct and indirect radiative forcing due to troposheric aerosols: A review, Review of Geophysics, 38, 513-543, 2000.

Haywood, J. M. and Shine, K. P.: Multi-spectral calculations of the direct radiative forcing of tropospheric sulphate and soot aerosols using a column model, Q. J. R. Meteorol. Soc., 123, 1907-1930, 1997.

Hering, S. and Cass, G.: The magnitude of bias in the measurement of PM2.5 arising from volatilisation of particulate nitrate from Teflon filters, J. Air \& Waste Manage. Assoc., 49, 725-733, 1999.

Heintzenberg, J., Müller, K., Birmili, W., Spindler, G., and Wiedensohler, A.: Mass related aerosol properties over the Leipzig Basin, J. Geophys. Res, 103, D11, 13 125-13 135, 1998.

IPCC, Climate Change 2001: The Scientific Basis, Contribution of Working Group I to the Third Assessment Report of the Intergovernmental Panel on Climate Change (IPCC), IPCC 2001.

Jacob, D. J.: Heterogeneous chemistry and tropospheric ozone, Atmos. Environ., 34, 2131-2159, 2000.

Jacobson, M. Z.: Global direct radiative forcing due to multicomponent anthropogenic and natural aerosols, J. Geophys. Res., 196, 1551-1568, 2001.

Janssen, A. J. and Asman, W. A. H.: Effective removal parameters in long-range air pollution transport models, Atmos. Environ., 22, 359-367, 1988.

Jeuken, A., Veefkind, J. P., Dentener, F., Metzger, S., and RoblesGonzalez, C.: Simulation of the aerosol optical depth over Europe for August 1997 and a comparison with observations, J. Geophys. Res., 106, 28 295-28 311, 2001.

Kasibhatla, P., Chameides, W. L., and John, J. S.: A threedimensional global model investigation of seasonal variations in the atmopheric burden of anthropogenic sulphate aerosols, J. Geophys. Res., 102, 3737-3759, 1997.

Kerminen, V. M., Hillamo, R., Teinila, K., Pakkanen, T., Allegrini, I., and Sparapani, R.: Ion balances of size-resolved tropospheric aerosol samples: implications for the acidity and atmospheric 
processing of aerosols, Atmos. Environ., 35, 31, 5255-5265, 2001.

Kerschbaumer, A. and Reimer, E.: Meteorological Data Preparation for the REM/CALGRID-model (in German), UBA-project 29943246, Freie Universität Berlin, Berlin, Germany, 2003.

Kiehl, J. T. and Briegleb, B. P.: The relative roles of sulphate and greenhouse gases in climate forcing, Science, 260, 311-314, 1993.

Koepke, P., Hess, M., Schult, I., and Shettle, E. P.: Global aerosol data set, Max-Planck-Institut für Meteorologie, Report No. 243, Hamburg, Germany, 1997.

Kouvarakis, G., Doukelis, Y., Mihalopoulos, N., Rapsomanikis, S., Sciare, J., and Blumthaler, M.: Chemical, physical, and optical characterization of aerosols during PAUR II experiment, J. Geophys. Res., 107, D18, 8141, doi:10.1029/2000JD000291, 2002.

Matthews, E.: Vegetation, land-use and seasonal albedo data sets: Documentation and archived data tape, NASA Tech. Memo, 86107, 1984

Meng, Z. and Seinfeld, J. H.: Timescales to achieve atmospheric gas-aerosol equilibrium for volatile species, Atmos. Environ., 30, 2889-2900, 1996.

Mentel, T. F., Sohn, M., and Wahner, A.: Nitrate effect in the heterogeneous hydrolysis of dinitrogen pentoxide on aqueous aerosols, Phys. Chem. Chem. Phys., 1, 5451-5457, 1999.

Metzger, S., Dentener, F. J., Pandis, S. N., and Lelieveld, J.: Gas/aerosol partitioning: 1. A computationally efficient model, J. Geophys. Res., 107, D16, doi:10.1029/2001JD001102, 2002a.

Metzger, S. M., Dentener, F. J., Jeuken, A., Krol, M., and Lelieveld, J.: Gas/aerosol partitioning II: Global modelling results, J. Geophys. Res., 107, D16, doi:0.1029/2001JD001103, 2002b.

Mozurkewich, M.: The dissociation constant of ammonium nitrate and its dependence on temperature, relative humidity and particle size, Atmos. Environ., 27A, 261-270, 1994.

Nenes, A., Pilinis, C., and Pandis, S. N.: Isorropia: A new thermodynamic model for multiphase multicomponent inorganic aerosols, Aquatic Geochemistry, 4, 123-152, 1998.

Nijenhuis, W. A. S. and Groten, S. M. E.: Surface cover related input data for 3-D atmospheric-chemistry models, NRSP-2, Proj.4.1/DE-01, 1999.

Poppe, D., Andersson-Skold, Y., Baart, A., Builtjes, P. J. H., Das, M., Diedler, F., Hov, O., Kirchner, F., Kuhn, M., Makar, P. A., Milford, J. B., Roemer, M. G. M., Ruhnke, R., Simpson, D., Stockwell, W. R., Strand, A., Vogel, B., and Vogel, H.: GasPhase Reactions in Atmospheric Chemistry and Transport Models: a Model Intercomparison, Eurotrac special publication, ISS, Garmisch-Partenkirchen, Germany, 1996.

Putaud, J.-P., Baltensperger, U., Brüggemann, E., Facchini, M. C., Fuzzi, S., Gehrig, R., Hansson, H.-C., Harrison, R. M., Jones, A. M., Laj, P., Maenhaut, W., Mihalopoulos, N., Müller, K., Palmgren, F., Querol, X., Rodriguez, S., Spindler, S., ten Brink, H. M., Tunved, P., Van Dingenen, R., Wehner, B., Weingartner, E., Wiedensohler, A., Wåhlin, P., and Raes, F.: A European Aerosol Phenomenology: physical and chemical characteristics of particulate matter at kerbside, urban, rural and background sites in Europe, JRC-IES report, http://ies.jrc.cec.eu.int/Download/cc, 2003.

Riemer, N., Vogel, H., Schell, B., Ackermann, I., Kessler, C., and Hass, H.: Impact of the heterogeneous hydrolysis of $\mathrm{N}_{2} \mathrm{O}_{5}$ on chemistry and nitrate aerosol formation in the lower troposphere under photosmog conditions, J. Geophys. Res., 108, D4, 4144, doi:10.1029/2002JD002436, 2003.

RIVM: Luchtkwaliteit, Jaaroverzicht 1995 (in English: Airquality, 1995 Results, RIVM Report 722101028, National Institute of Public Health and the Environment, Bilthoven, The Netherlands, 1997.

Robles-Gonzalez, C., Veefkind, J. P., and de Leeuw, G.: Aerosol optical depth over Europe in August 1997 derived from ATSR-2 data, Geophys. Res. Lett., 27, 955-958, 2000.

Robles-Gonzalez, C., Schaap, M., de Leeuw, G., Builtjes, P. J. H., and van Loon, M.: Spatial variation of aerosol properties derived from satellite observations, Atmos. Chem. Phys., 3, 1-13, 2003.

Roelofs, G. J., Kasibhatla, P., Barrie, L., Bergmann, D., Bridgeman, C., Chin, M., Christensen, J., Easter, R., Feichter, J., Jeuken, A., Kjellstrom, E., Kock, D., Land, C., Lohmann, U., and Rasch, P. Analysis of regional budgets of sulphur species modeled for the COSAM exercise, Tellus, 53B, 673-694, 2001.

Roemer, M.: The tropospheric budgets and trends of methane, carbon $\mathrm{moNO}_{\mathrm{X}}$ ide and ozone on a global scale, TNO-publication P95/035, Delft, The Netherlands, 1995.

Roemer, M., Beekmann, M., Bergström, R., Boersen, G., Feldmann, H., Flatøy, F., Honore, C., Langner, J., Jonson, J. E., Matthijsen, J., Memmesheimer, M., Simpson, D., Smeets, P., Solberg, S., Stern, R., Stevenson, D., Zandveld, P., and Zlatev, Z.: Ozone trends according to ten dispersion models, Eurotrac publication in press, Eurotrac-ISS, Garmisch Partenkirchen, Germany, 2003.

Schaap, M., Muller, K., and ten Brink, H. M.: Constructing the European aerosol nitrate concentration field from experimental data, ECN-report RX-01-033, ECN, Petten, The Netherlands, 2001.

Schaap, M., Muller, K., and ten Brink, H. M.: Constructing the European aerosol nitrate concentration field from quality analysed data, Atmos. Environ., 36, 8, 1323-1335, 2002a.

Schaap, M., van Loon, M., Visschedijk, A., Dentener, F. J., and Builtjes, P. J. H.: Modelling PM2.5 concentrations over Europe: the role of agriculture, Landbauforschung Völkenrode, Special Issue 235, 49-55, 2002b.

Schaap, M.: On the importance of aerosol nitrate in Europe, $\mathrm{PhD}$ thesis, University of Utrecht, Utrecht, The Netherlands, 2003.

Schaap, M., Spindler, G., Schulz, M., Acker, K., Maenhaut, W., Berner, A., Wieprecht, W., Streit, N., Müller, K., Brüggemann, E., Putaud, J.-P., Puxbaum, H., Baltensperger, U., and ten Brink, H. M.: Artefacts in the sampling of nitrate studied in the "INTERCOMP" campaigns of EUROTRAC-AEROSOL, Atmos. Environ., in press, 2004

Schulz, M., Van Beusekom, J., Bigalke, K., et al.: The atmospheric impact on fluxes of nitrogen, POPs and energy in the German Bight, Deutsche Hydrographische Zeitschrift, 51, 133 154, 1999.

Tamm, S. and Schulz, M.: Open ocean aerosol composition obtained during 15 months on a North Sea ferry, Atmos. Environ., 37, S133-S143, Suppl. 1, 2003.

Tarrason, L. and Iversen, T.: Modelling intercontinental transport of atmospheric sulphur in the northern hemisphere, Tellus B, 50, 4, 331-352, 1998.

Ten Brink, H. M., Kruisz, C., Kos, G. P. A., and Berner, A.: Composition/size of the light-scattering aerosol in The Netherlands, Atmos. Environ., 31, 3955-3962, 1997. 
Ten Brink, H. M., Hensen, A., Khystov, A., van Dorland, R., Jeuken, A., van Velthoven, P., Lelieveld, J., van den Berg, A., Swart, D. P. J., Bergwerff, J. B., and Apituley, A.: Aerosol; cycle and influence on the radiation balance, Cluster-project in the National Research Program on Global Air Pollution and Climate Change, npr2, report no. 410200064, 2001.

Ten Brink, H. M. and Schaap, M.: Aerosol Nitrate, a Dominant Atmospheric Trace Component in Europe?!, Proceedings of the workshop: Air Pollution as a Climate Forcing, 29 April-3 May 2002, Honolulu, Hawaii, http://www.giss.nasa.gov/ meetings/pollution02/d2/tenbrink.html, 2002.

Thöni, L., Seitler, E., Schnyder, N., Künzli, B., and Marti, S.: Depositionsuntersuchungen im Kanton Zürich - Wallisellen: Resultate 1999, Wallisellen und Bachtel: Entwicklung über die Jahre, FUB-report, FUB, Rapperswill, Switzerland, 2000.

TNO: The CEPMEIP emission database, http://www.air.sk/tno/ cepmeip, 2001.

Tsyro, S.: First estimates of the effect of aerosol dynamics in the calculation of PM10 and PM2.5, EMEP report MSC-W Note 4/02, Norwegian Meteorological Institute, Oslo, Norway, 2002.

Van der Hoek, K. W.: Estimating ammonia emission factors in Europe: Summary of the work of the UNECE ammonia expert panel, Atmos. Environ., 32, 3, 315-316, 1998.

Van Dorland, R., Dentener, F. J., and Lelieveld, J.: Radiative forcing due to tropospheric ozone and sulphate aerosols, J. Geophys. Res., 102, D23, 28 079-28 100, 1997.
Veefkind, J. P., van der Hage, J. C. H., and ten Brink, H. M.: Nephelometer derived and directly measured aerosol optical depth of the atmospheric boundary layer, Atmos. Res., 41, 217-228, 1996.

Verwer, J. G.: Gauss-Seidel iteration for stiff ODEs from chemical kinetics, SIAM J. Sci. Comput., 15, 1243-1250, 1994.

West, J. J., Pilinis, C., Nenes, A., and Pandis, S. N.: Marginal direct climate forcing by atmospheric aerosols, Atmos. Environ., 32, 2531-2542, 1998.

West, J. J., Ansari, A. S., and Pandis, S. N.: Marginal PM2.5: Nonlinear Aerosol Mass Response to Sulphate Reductions in the Eastern United States, J. Air \& Waste Manage. Assoc., 49, 14151424, 1999.

Whitby, K. T.: The physical characteristics of sulphur aerosols, Atmos. Environ., 12, 135-159, 1978.

Whitten, G., Hogo, H., and Killus, J.: The Carbon Bond Mechanism for photochemical smog, Env. Sci. Techn. 14, 14690-14 700, 1980.

Zhang, Y., Seigneur, C., Seinfeld, J. H., Jacobson, M., Clegg, S. L., and Binkowski, F. S.: A comparative review of inorganic aerosol thermodynamic equilibrium modules: differences, and their likely causes, Atmos. Environ., 34, 117, 2000.

Zimmerling, R., Daemmgen, U., and Behrens, U.: Konzentrationen versauernd und eutrophierend wirkender Spurengase und Aerosol-Bestandteile in Nordost-Brandenburg, Landbauforschung Volkenrode, special issue, 213, 43-93, 2000. 